\title{
Nano-Sized and Mechanically Activated Composites: Perspectives for Enhanced Mass Burning Rate in Aluminized Solid Fuels for Hybrid Rocket Propulsion
}

\section{Christian Paravan}

Space Propulsion Laboratory (SPLab), Aerospace Science and Technology Department, Politecnico di Milano, 34, via La Masa, 20156 Milan, Italy; christian.paravan@polimi.it; Tel.: +39-02-2399-8068

Received: 31 May 2019; Accepted: 18 November 2019; Published: 25 November 2019

\begin{abstract}
This work provides a lab-scale investigation of the ballistics of solid fuel formulations based on hydroxyl-terminated polybutadiene and loaded with Al-based energetic additives. Tested metal-based fillers span from micron- to nano-sized powders and include oxidizer-containing fuel-rich composites. The latter are obtained by chemical and mechanical processes providing reduced diffusion distance between $\mathrm{Al}$ and the oxidizing species source. A thorough pre-burning characterization of the additives is performed. The combustion behaviors of the tested formulations are analyzed considering the solid fuel regression rate and the mass burning rate as the main parameters of interest. A non-metallized formulation is taken as baseline for the relative grading of the tested fuels. Instantaneous and time-average regression rate data are determined by an optical time-resolved technique. The ballistic responses of the fuels are analyzed together with high-speed visualizations of the regressing surface. The fuel formulation loaded with $10 \mathrm{wt} \%$ nano-sized aluminum (ALEX-100) shows a mass burning rate enhancement over the baseline of $55 \% \pm 11 \%$ for an oxygen mass flux of $325 \pm 20 \mathrm{~kg} /\left(\mathrm{m}^{2} \cdot \mathrm{s}\right)$, but this performance increase nearly disappears as combustion proceeds. Captured high-speed images of the regressing surface show the critical issue of aggregation affecting the ALEX-100-loaded formulation and hindering the metal combustion. The oxidizer-containing composite additives promote metal ignition and (partial) burning in the oxidizer-lean region of the reacting boundary layer. Fuels loaded with $10 \mathrm{wt}$ \% fluoropolymer-coated nano-Al show mass burning rate enhancement over the baseline $>40 \%$ for oxygen mass flux in the range 325 to $155 \mathrm{~kg} /\left(\mathrm{m}^{2} \cdot \mathrm{s}\right)$. The regression rate data of the fuel composition loaded with nano-sized Al-ammonium perchlorate composite show similar results. In these formulations, the oxidizer content in the fuel grain is $<2 \mathrm{wt}$. $\%$, but it plays a key role in performance enhancement thanks to the reduced metal-oxidizer diffusion distance. Formulations loaded with mechanically activated ALEX-100-polytetrafluoroethylene composites show mass burning rate increases up to $140 \% \pm 20 \%$ with metal mass fractions of $30 \%$. This performance is achieved with the fluoropolymer mass fraction in the additive of $45 \%$.
\end{abstract}

Keywords: nano-sized aluminum; micron-sized aluminum; fluoropolymer; mechanically activated aluminum; coated aluminum; fuel-rich composite powder; aluminum aggregation; aluminum agglomeration; regression rate; mass burning rate

\section{Introduction}

Hybrid rocket engines (HREs) feature a diffusion-limited combustion process between the atomized liquid (or gaseous) oxidizer and the pyrolyzed/vaporized solid fuel. The turbulent boundary layer combustion is ruled by convective heat transfer, with the $r_{f}$ showing relatively strong dependence on $G$ [1-5]. In the complex boundary layer combustion mechanism, oxidizer-lean conditions are encountered in the region extending from the regressing surface to the flame. Conventional 
polymer-based solid fuels feature relatively slow $r_{f}$, in turn yielding low thrust levels with simple grain geometries (i.e., cylindrical grains with single central port perforation). This issue can be partially overcome by multi-port grains enabling increased $\dot{m}_{f}$ thanks to the enlarged burning surface area. Such a solution requires complex implementation, with possible system dry mass increases and structural integrity issues [6]. Liquefying fuels show faster regression rates than conventional polymeric formulations thanks to the entrainment of melted fuel droplets $[7,8]$. On the other hand, liquefying fuels such as paraffin wax feature weak mechanical properties and are unsuitable for effective exploitation in operating systems. Different studies are currently ongoing to obtain reinforced fuel grains combining ballistic and mechanical properties. Paraffin wax blending with reinforcing polymers is a strategy to achieve this purpose [9-14]. The improved mechanical properties of the blended formulations are accompanied by increased viscosity of the melted phase; this lessens the entrainment mass transfer, thus decreasing $r_{f}$ and $\dot{m}_{f}$. In spite of differences in the combustion mechanism of polymeric and liquefying fuels, both kinds of formulations can achieve increased ballistic performance thanks to the use of metal-based energetic additives [15-19].

Metal-based energetic additives aim at providing enhanced flame temperatures and/or increased radiation heat transfer to promote faster $r_{f}$ of the solid fuel grain and increased $\dot{m}_{f}$. Moreover, augmented radiation heat transfer reduces the $r_{f}(G)$ dependence, enabling solid fuel ballistic response tailoring [20]. Aluminum is an attractive candidate as an energetic filler, thanks to its oxidation enthalpy [21] and its commercial availability at different dispersity levels (from micron-sized particles to the nanoscale), enabling its use as it is, or as an ingredient for composite additives [22-24].

Conventional Al powders feature micron-sized spherical particles [25]. The $\mu \mathrm{Al}$ is typically air-passivated, thus showing a core-shell particle structure with the metal core surrounded by an amorphous $\mathrm{Al}_{2} \mathrm{O}_{3}$ layer [26-28]. The micrometric size, together with the particle morphology and the specific surface area (SSA) $<1 \mathrm{~m}^{2} / \mathrm{g}$, yields $\mu \mathrm{Al}$ high metal content (typically $>95 \mathrm{wt} . \%$ ), relatively low reactivity, and inherent safety (i.e., high ignition temperature, reduced dispersion in air, and limited aging influence) [28-31]. The reactivity of $\mu \mathrm{Al}$ can be enhanced by reducing the particle size down to the nanoscale [32-35] and by activation processes [23,24,36-39]. Nano-sized $\mathrm{Al}$ is characterized by SSA $\sim 10 \mathrm{~m}^{2} / \mathrm{g}$ (or higher, depending on the average powder particle size and size distribution). These powders show marked reactivity at temperatures lying below the Al melting point (933 K) $[17,34,35,40]$. Nano-sized $\mathrm{Al}$ is typically passivated by air, although special chemicals may be used to shield the metal from the external environment $[34,35,40]$. With respect to $\mu \mathrm{Al}$, air-passivated $\mathrm{nAl}$ exhibits reduced $C_{A l}$ and increased sensitivity to storage conditions [28]. Due to the reduced size, the nAl powders feature cold-cohesion phenomena. Clusters of particles exhibit SSA reduction with respect to the single particles. Thus, special manufacturing procedures are typically implemented to disperse nAl in energetic compositions [41-43]. Moreover, the use of nano-sized particles is complicated by their effects on propellant/fuel slurry rheology $[25,44]$, and stricter safety requirements than the micron-sized counterpart. Activated $\mathrm{Al}$ powders typically feature reactivity tailoring of the starting material by chemical, mechanical, and mechano-chemical methods [22-24]. Activation techniques modify the powder surface characteristics (such as SSA and/or composition), and/or the particle morphology, size, and composition [22-24,36-38,45-48]. In particular, activation processes enable the creation of composite additives such as dual-metal [38,48] or metal-oxidizer compositions [45,48], offering wide possibilities for additive reactivity tailoring. Focusing on mechanical activation (i.e., ball milling), it is worth noting that the additives produced from micron-sized granules typically feature flake shape. For this particle morphology, thickness is the only nanoscale dimension, while complex surface texture (typically providing increased SSA with respect to conventional $\mu \mathrm{Al}$ ) is usually achieved. Thanks to this, these materials offer increased reactivity while reducing the issues related to the difficult handling of nano-sized materials [48]. The creation of composite additives eases the propellant/fuel manufacturing, enabling the use of a single (dual) ingredient, instead of adding/handling different materials.

The presence of metal additives, including $\mathrm{Al}$, implies the possible insurgence of performance losses due to incomplete metal combustion, two-phase flow expansion, and residual accumulation 
in the combustion chamber/nozzle walls [17-22]. All these issues are of particular relevance in HRE combustion due to the diffusion-limited mechanism and the relatively low combustion efficiency of these systems. The mitigation of the low combustion efficiency requires specific implementations such as mixing chambers and/or the design of energetic additives featuring tailored composition and reactivity to lessen the detrimental effects related to metal combustion.

Current open literature includes several experimental studies on the $r_{f}$ behavior of metallized solid fuels for hybrid rocket propulsion [15-17,22,49-56]. In these works, differences in additive characterization approaches, experimental operating conditions, and data reduction techniques possibly yield difficult interpretations of the effects of the investigated materials when comparing different studies.

This work investigates the effects of different Al-based energetic additives on the ballistic response of polymer-based fuels for hybrid rocket propulsion. The objectives of this work are (i) evaluating the $r_{f}$ and $\dot{m}_{f}$ enhancement offered by innovative Al-based additives, and (ii) analyzing the surface phenomena occurring during the combustion of metallized formulations to link the additive composition effects to the solid fuel ballistic response. Hydroxyl-terminated polybutadiene (HTPB) is considered as a binder in the solid fuel formulations, in light of its suitable mechanical properties [42], making it an interesting candidate for the lab-scale study, as well as for possible applications requiring high volumetric efficiency pursued by high filler loads. The information gained by insight into the burning behavior of polymer-based fuels can provide useful suggestions for the development of energetic additives suitable for paraffin-based fuels reinforced by blending with thermoplastic polymers, in which the entrainment reduction due to the increased melt layer viscosity could be compensated for by using energetic fillers. The investigated additives range from conventional $\mu \mathrm{Al}$ to $\mathrm{nAl}$, and the test matrix includes mechanical-activated powders. The tested $\mathrm{nAl}$ powders feature different passivation layers and are either uncoated or coated. Investigated mechanical-activated powders are based on $\mu \mathrm{Al}$ and nAl. Composite powders are fuel-rich formulations including ammonium perchlorate (AP), a copolymer of vinylidene fluoride and hexafluoropropylene (VFHFP) [57], and polytetrafluoroethylene (PTFE) as oxidizers. Composite additives are produced by chemical methods (i.e., particle coating) and mechanical activation. Both approaches aim at reducing the diffusion distances between the $\mathrm{AP} /$ fluoropolymer and the metal fuel particles. The composites are formulated to deliver the oxidizing species close to the metal fuel during the combustion. The pursued effects are a prompter $\mathrm{Al}$ ignition and combustion in the oxidizer-lean region close to the gasifying fuel surface. The proposed strategy differs from mixed fuel approaches previously presented in the open literature [58,59]. In the current work, the oxidizer is localized in the composite additive, and fluoropolymers are selected as oxidizers due to their relatively high thermal stability joined with reactivity in the presence of metals such as Al. In general, the oxidizer-loaded solid fuels possibly imply a loss of some of the HRE peculiarities such as faint $r_{f}$ dependence on the $p_{c}$ (in turn simplifying throttling operations and granting combustion tolerance to grain cracks), stop-restart capability, and reduced environmental impact. The current work focuses on the combustion behavior of metallized solid fuels, and on the analysis of the surface phenomena involved in this process; therefore, the abovementioned effects are not considered in this study. On the other hand, it is worth noting that the operating flexibility of HREs is not lost in the presence of solid fuel grains embedding oxidizing substances, unless the resulting formulation is burnt above its pressure deflagration limit (PDL). The latter is the lowest pressure a solid propellant/mixed hybrid can exhibit self-sustained combustion at. If a mixed hybrid is burning at $p_{c}<\mathrm{PDL}$, the combustion can be stopped and restarted without differences from what occurs in an equivalent fuel composition with no oxidizer load [59].

The work starts with pre-burning characterization of the investigated materials, and then focuses on the burning behavior of the HTPB-based fuels. The ballistic responses of the fuel formulations are characterized by time-resolved $r_{f}$ and $\dot{m}_{f}$ measurements and by high-speed visualizations of the burning surface. 
This work aims at providing a detailed view of the combustion process of aluminized fuel formulations. Pre-burning characterization of the metal additives is analyzed together with time-resolved ballistics of the loaded fuels. In the open literature, solid fuel combustion behavior is typically evaluated by time- and space-averaged data reduction techniques based on pre- and post-firing measurements of relevant parameters. The time-resolved technique for $r_{f}$ and $\dot{m}_{f}$ tracks the combustion evolution from ignition to the final condition, providing the fuel ballistic response over a range of $G_{o x}$ with a single test. High-speed visualizations of the burning surface phenomena offer detailed insight into the effects of the metal additives on the fuel combustion behavior, and they enable evaluating the impact of aggregation/agglomeration phenomena on the combustion of Al-based additives. These effects are not widely investigated for solid fuel formulations. The combination of ballistic analyses and surface visualizations contributes to clarifying the reasons for some contrasting results observed in the open literature for the combustion of aluminized fuels, in particular when nAl formulations are considered.

\section{Background}

A background of the current work is hereby presented considering open literature studies focused on (i) the fundamentals of the solid fuel combustion process, (ii) the influence of metal additives on the solid fuel ballistics, and (iii) a discussion of $\mathrm{Al}$ aggregation and agglomeration phenomena (with particular emphasis on solid fuel formulations).

\subsection{Fundamentals of Solid Fuel Combustion Process}

In hybrid rockets, the flame has a diffusive nature, and it is set in the boundary layer generated by the oxidizer flow over the grain surface. Fundamentals of the HRE combustion mechanism were reviewed by Chiaverini [4] and Marquardt and Majdalani [5]. A survey on solid fuel thermal decomposition (a phenomenon playing a central role in HRE combustion) was given by Lengellé [60]. The behavior of non-metallized polymeric fuel formulations is dominated by convective heat transfer, and it is subject to heat transfer blockage due to mass blowing from the surface [1-3]. Under these conditions, theoretical modeling of the combustion mechanism yields $r_{f}(G)=a_{r} \cdot G^{n_{r}}$ (or $\left.r_{f}\left(G_{o x}\right)=a_{r} \cdot G_{o x}^{n_{r}}\right)$, with $n_{r}=0.8$ [1-3]. Experimental investigations typically yield $r_{f}(G)$ power law approximations with $n_{r}$ in the range 0.6 to 0.8 [4]. Radiation heat transfer plays a role as convective phenomena are lessened $[4,20,61,62]$. The effects of radiation are due to gas radiation (playing a minor role), to soot, and (if present) to radiating metal particles [1-5,20,61-63]. Under the influence of radiation heat transfer, $r_{f}$ may exhibit $p_{c}$ dependence $[4,20]$, and the $r_{f}(G)$ power law approximation shows $n_{r}<0.8[1-5,20,61-63]$. Liquefying fuels show a regression rate dependence on $G$ similar to the polymeric formulations, although their $r_{f}$ exhibits percentage increases of $300-400 \%$ with respect to reference HTPB $[7,8]$. This enhanced performance is achieved thanks to an instability of the melt fuel layer formed at the regressing surface. If this layer features low viscosity and reduced surface tension, its interaction with the oxidizer stream yields the formation of waves from which melt fuel droplets are detached $[7,8]$. Therefore, in liquefying fuels the overall $r_{f}$ is the sum of the vaporization and of the entrainment contributions. The latter does not affect the convective heat transfer blockage; moreover, the entrained mass flow rate does not require vaporization enthalpy absorption at the regressing surface $[7,8]$. Current liquefying fuels offer low mechanical properties. Typical mechanical properties reinforcement techniques yield a reduction of the entrainment effect due to the augmented viscosity of the melted fuel layer [10-14,19]. Recent efforts proposed innovative reinforcing strategies exerting minor effects on the liquid phase viscosity such as self-disintegrating structures [64], as well as the use of three-dimensional (3D) printed cellular structures $[65,66]$.

The diffusion-limited combustion of HREs implies low combustion efficiency, thus requiring specific countermeasures such as enhanced oxidizer-fuel vapors mixing in the aft-combustion chamber and/or the use of diaphragms [67], non-conventional oxidizer injection implementations (playing a role in $r_{f}$ enhancement) [68-70], and/or design of special engine configurations [71]. 


\subsection{Regression Rate Performance and Metal Additives}

For both polymer- and paraffin-based fuel formulations, augmented or tailored, $r_{f}$ performance is typically pursued by loading the fuel grains with energetic additives such as oxidizer, metal, and hydride powders. A comprehensive review of the early steps of this approach was given by Risha et al. in [15]. First studies on the combustion of metal-loaded fuels investigated the effects of micron-sized additives (such as $\mathrm{Al}$ and $\mathrm{Mg}$ ). In these analyses, the achieved $r_{f}$ enhancements were mainly due to the augmented radiation heat transfer caused by the presence of metal particles, the effect on the flame temperature being limited by the high ignition temperatures, and relatively long burning times of these conventional additives $[15,20,61,62]$. Different analyses showed that $\mu \mathrm{Al}$ exerts no marked influence on the $r_{f}$ by particle sizes in the range of 30 to $250 \mu \mathrm{m}[15,20,61,62]$. Thanks to their enhanced reactivity over the micron-sized counterpart, nanometric additives disclose new opportunities for solid fuel performance enhancement. In general, the lower ignition temperatures and the shorter combustion times of nano-sized particles should promote increased $r_{f}[15-18,40,41,50-54]$, as well as relatively high combustion efficiencies [55]. On the other hand, the open literature shows contrasting results for fuel formulations loaded with $\mathrm{nAl}$. The ballistic responses of HTPB-based fuels doped with different nano-sized ingredients was extensively investigated by Risha et al. [50-52]. In these studies, $r_{f}$ variations were observed for different sets of formulations featuring similar compositions [50-52]. These effects were probably due to different manufacturing procedures (without/with fuel slurry sonication). Results for HTPB + $13 \mathrm{wt} . \% \mathrm{nAl}$ (air-passivated, nominal size 100-150 nm, SSA = 13 $\left.\mathrm{m}^{2} / \mathrm{g}\right)$, exhibited a $r_{f}$ enhancement over the HTPB baseline of $105 \%\left(G_{o x}=112 \mathrm{~kg} /\left(\mathrm{m}^{2} \cdot \mathrm{s}\right)\right)$ [52]. In the same dataset, formulations loaded with Viton-A-coated $\mathrm{nAl}$ and $\mu \mathrm{Al}$ showed an $r_{f}$ increase (relative to the baseline) of $123 \%$ and $142 \%$, respectively [52]. Experimental evidences suggest an easier ignition and a more complete combustion of the fluoropolymer coated powder with respect to the other tested additives. The data presented in References [55,56] show moderate (if any) $r_{f}$ enhancement for nAl-loaded formulations. In the work of Thomas et al. [56], the absence of marked effects of the $\mathrm{nAl}$ on the solid fuel ballistic response of HTPB-based fuels was probably due to the limited additive mass fraction ( $5 \mathrm{wt} . \%)$. In a recent study, Connell et al. reported a maximum $r_{f}$ increase of $20 \%$ over a non-metallized baseline for HTPB + $10 \mathrm{wt} . \% \mathrm{nAl}$ [72]. In the same study, results on innovative Ti-Al-B nanopowders were presented. These new additives showed $r_{f}$ effects similar to the aforementioned nAl, but with a reduced $G_{0 x}$ sensitivity [72]. The ballistic response of a paraffin-based fuel formulation loaded with micron-sized Al flakes (with nano-metric thickness) was presented in Reference [18]. The metallized fuel promoted an $r_{f}$ enhancement over a pure paraffin formulation, although slight differences in operating conditions prevented a precise relative grading. Galfetti et al. reported significant performance benefits achieved by the use of $\mathrm{nAl}$ (nominal sizes of $50 \mathrm{~nm}$ and $100 \mathrm{~nm}$ ) in entrainment-producing fuels tested in a lab-scale slab burner [19]. The solid fuel $r_{f}$ increase over an HTPB baseline was $186 \%$ for pure solid wax fuel, while it reached $210 \%$ for nAl-doped compositions.

Fuel formulations loaded with AP produce $r_{f}$ increases over an HTPB-baseline up to $300 \%$ for a solid oxidizer mass fraction of $25 \mathrm{wt} . \%$ [59]. Reference [73] discussed the characteristics and the performance of a solid fuel formulation with $80 \mathrm{wt} . \%$ PTFE $+20 \mathrm{wt} . \% \mathrm{~B}$ that is considered for specific hybrid propulsion applications.

Mechanical, chemical, and mechano-chemical activation processes offer breakthrough opportunities for the development of new energetic composites [22-24,36-39,45-48]. The use of mechanical and mechano-chemical activation processes enables coupling ingredients featuring relatively low compatibility [24,45]. Detailed discussions on the design strategy for mechanically activated powders were presented in Reference [24]. Micron-sized Al-rich composites containing PTFE and produced by mechanical activation were presented in Reference [74]. In the analysis, a paraffin and ethylene-vinyl acetate blend was loaded with an Al + PTFE composite and featured a $300 \% r_{f}$ increase over the non-metallized counterpart. 


\subsection{Aluminized Solid Fuel Formulations: Aggregation and Agglomeration}

Aluminum combustion under solid/hybrid rocket motor conditions implies the presence of condensed combustion products (CCPs) [75-78]. Condensed products feature different compositions, morphologies, and sizes, depending on their genesis conditions (i.e., solid propellant/fuel composition details and operating conditions). Following the nomenclature introduced in Reference [77], CCPs include (i) smoke-oxide particles (SOP), and (ii) agglomerates. The SOP consist of fine particles $(<1 \mu \mathrm{m})$ formed by condensation of gaseous reaction products and combustion of non-agglomerated particles [77]. Agglomerates are composed by $\mathrm{Al}$ and $\mathrm{Al}_{2} \mathrm{O}_{3}$ (with the eventual presence of binder decomposition products). Agglomerates feature enlarged size with respect to the original Al powder particles loaded in the solid propellant/fuel grain. This size growth is caused by aggregation of single particles at the burning propellant surface/subsurface, and by the coalescence of agglomerates (possibly followed by particle breakup during expansion) [79]. A larger agglomerate particle size and mass fraction results in higher performance losses due to incomplete combustion and two-phase flow [17]. Experimental and numerical studies on the $\mathrm{Al}$ combustion in solid propellant formulations were discussed in References [75-83].

The burning behavior of HTPB-based formulations doped with high mass fractions of $\mu \mathrm{Al}$ was presented in Reference [61]. In this study by Strand et al., $7 \mathrm{~kg} /\left(\mathrm{m}^{2} \cdot \mathrm{s}\right) \leq G_{o x} \leq 35 \mathrm{~kg} /\left(\mathrm{m}^{2} \cdot \mathrm{s}\right)$, and the investigated fuel featured $30 \mathrm{wt} . \% \mathrm{Al}$ powder and $30 \mathrm{wt} . \%$ coal (added to the formulation to segregate the metal particles). Experimental results showed a layered combustion. The formation of an HTPB-coal melt containing Al was observed. Filigrees/flakes protruded from the regressing surface to the reaction zone, and large-size particles $(\sim 1 \mathrm{~mm})$ were ejected by the regressing surface. During motor firings on different lab-scale set-ups, Risha et al. noted different $r_{f}$ performance from similar aluminized formulations loaded with Al flakes with nanometric thickness [15]. SEM images of extinguished fuel grains showed the more abundant $\mathrm{Al}$ melt layer accumulation at the regressing surface of the larger motor and causing the lower $r_{f}$. Observation of aggregation and incipient agglomeration of $\mu \mathrm{Al}-$ and nAl-loaded fuels and mixed hybrid compositions were reported in References $[17,84]$ where high-speed and high-magnification visualizations were performed. The captured high-speed images showed localized particle aggregation phenomena affecting the investigated fuels that were tested under low $G_{o x}\left(10 \mathrm{~kg} /\left(\mathrm{m}^{2} \cdot \mathrm{s}\right)\right)$ with the use of $60 \mathrm{wt} . \% \mathrm{O}_{2}+40 \mathrm{wt} . \% \mathrm{~N}_{2}$ as oxidizer.

\section{Investigated Materials}

\subsection{Aluminum and Al-Based Powders}

An overview of the tested $\mathrm{Al}$ powders and Al-based composites is reported in Table 1. A conventional micron-sized $\mathrm{Al}(\mu \mathrm{Al} 15)$ was taken as the reference for relative grading of the additives. Two different families of Al-based energetic materials are presented: (a) nAl passivated by different methods and without/with coating, and (b) mechanically activated metal powders and fuel-rich composites based on both $\mu \mathrm{Al}$ and nAl. AP, VFHFP, and PTFE were included in nano- and/or micron-sized fuel-rich composites. Composite powders exploited the oxidizing species release from the oxidizer/fluoropolymer decomposition to trigger metal ignition and to provide (partial) metal oxidation in the fuel-rich conditions encountered close to the solid grain regressing surface. Table 2 provides the relative grading of $T_{f l}$ for $\mathrm{Al}$ composites (heat of formation for VFHFP and PTFE from References [85-87], respectively). The $\mathrm{Al}+\mathrm{AP}$ combustion at $1.0 \mathrm{MPa}$ for oxidizer content $\geq 15 \mathrm{wt} . \%$ yielded a $T_{f l}$ exceeding the melting point of $\mathrm{Al}_{2} \mathrm{O}_{3}(\sim 2300 \mathrm{~K})$. The VFHFP offered reduced calculated flame temperature with respect to PTFE due to the lower F content (66 wt.\% vs. $76 \mathrm{wt.} \%$ ) $[57,87]$. Focusing on the oxidizer densities, PTFE featured the highest value. This characteristic is of interest for the design of composites with high densities for enhanced $\dot{m}_{f}$. 
Table 1. Investigated powders: nomenclature, description, and production details (LE: low energy; HE: high energy; MA: mechanical activation; PTFE: polytetrafluoroethylene; ALEX: aluminum exploded).

\begin{tabular}{|c|c|c|c|}
\hline Powder Id. & $\begin{array}{l}\text { Powder Description } \\
\text { and Notes }\end{array}$ & $\begin{array}{l}\text { Particle Surface } \\
\text { Composition }\end{array}$ & $\begin{array}{l}\text { Producer and } \\
\text { References }\end{array}$ \\
\hline$\mu \mathrm{Al} 15$ & $\begin{array}{l}\text { Air-passivated } \mu \mathrm{Al} \text { with } \\
\text { nominal size of } 15 \mu \mathrm{m}\end{array}$ & \multirow[b]{2}{*}{$\mathrm{Al}_{2} \mathrm{O}_{3}$} & \multirow[b]{2}{*}{ AMG Alpoco (UK) [25] } \\
\hline$\mu \mathrm{Al} 7.5$ & $\begin{array}{l}\text { Air-passivated } \mu \mathrm{Al} \text { with } \\
\text { nominal size of } 7.5 \mu \mathrm{m}\end{array}$ & & \\
\hline ALEX-100 & $\begin{array}{l}\text { Air-passivated } \mathrm{nAl} \text { with } \\
\text { nominal size of } 100 \mathrm{~nm}\end{array}$ & \multirow[b]{2}{*}{$\mathrm{Al}_{2} \mathrm{O}_{3}$} & \multirow{6}{*}{$\begin{array}{c}\text { Advanced Powder } \\
\text { Technology LLC (Tomsk, } \\
\text { Russia) }[40,54]\end{array}$} \\
\hline ALEX-50 & $\begin{array}{l}\text { Air-passivated } \mathrm{nAl} \text { with } \\
\text { nominal size of } 50 \mathrm{~nm}\end{array}$ & & \\
\hline ALEX-100B & $\begin{array}{l}\text { ALEX-100 coated with } \\
0.2 \text { wt.\% pyrocatechol } \\
\left(\mathrm{C}_{6} \mathrm{H}_{6} \mathrm{O}_{2}\right)\end{array}$ & $\mathrm{C}_{6} \mathrm{H}_{6} \mathrm{O}_{2}$ & \\
\hline L-ALEX-100 & $\begin{array}{l}\text { Stearic acid coated } \\
\text { ALEX-100 }\end{array}$ & $\mathrm{C}_{17} \mathrm{H}_{35} \mathrm{COOH}$ & \\
\hline VF-ALEX-100F & $\begin{array}{l}\text { Fluorotelomer } \\
\text { alcohol-derived } \\
\text { ester-coated ALEX-100 } \\
\text { (coating solvent removed } \\
\text { by filtration) }\end{array}$ & \multirow{2}{*}{$\begin{array}{l}\text { Vinylidene } \\
\text { fluoride-hexafluoropropylene } \\
\text { (70:30) copolymer } \\
\text { (VFHFP) + ester }\end{array}$} & \\
\hline VF-ALEX-50E & $\begin{array}{l}\text { Fluorotelomer } \\
\text { alcohol-derived } \\
\text { ester-coated ALEX-50 } \\
\text { (coating solvent removed } \\
\text { by evaporation) }\end{array}$ & & \\
\hline AP15-ALEX-100B & $\begin{array}{l}\text { AP }(15 \text { wt. } \%)+ \\
\text { ALEX-100B }(85 \text { wt. } \%), \\
\text { ALEX-100B clustered } \\
\text { and coated by AP } \\
\text { (solvent removal by } \\
\text { evaporation) }\end{array}$ & $\begin{array}{c}\mathrm{Al}_{2} \mathrm{O}_{3}+\mathrm{C}_{6} \mathrm{H}_{6} \mathrm{O}_{2}+ \\
\mathrm{NH}_{4} \mathrm{ClO}_{4}\end{array}$ & SPLab \\
\hline LE- $\mu$ Al15 & Low-energy MA, $\mu$ Al15 & \multirow{6}{*}{$\mathrm{Al}_{2} \mathrm{O}_{3}+\left(\mathrm{C}_{2} \mathrm{~F}_{4}\right)_{\mathrm{n}}$} & \multirow{6}{*}{$\begin{array}{c}\text { SPLab } \\
\text { (MA procedure) }[23,24]\end{array}$} \\
\hline LE- $\mu$ Al15-T10 & $\begin{array}{l}\text { Low-energy MA, } \mu \text { A15 } \\
(90 \text { wt. } \%)+\text { PTFE (10 } \\
\text { wt. } \%)\end{array}$ & & \\
\hline LE- $\mu$ Al15-T30 & $\begin{array}{l}\text { Low-energy MA, } \mu \text { Al15 } \\
\text { (70 wt. } \%)+ \text { PTFE (30 } \\
\text { wt. } \%)\end{array}$ & & \\
\hline LE- $\mu \mathrm{Al} 7.5-\mathrm{T} 30$ & $\begin{array}{l}\text { Low-energy MA, } \mu \mathrm{Al7} .5 \\
(70 \text { wt. } \%)+\text { PTFE ( } 30 \\
\text { wt. } \%)\end{array}$ & & \\
\hline HE- $\mu$ Al15-T45 & $\begin{array}{l}\text { High-energy MA, } \mu \text { Al15 } \\
\text { (55 wt.\%) + PTFE (45 } \\
\text { wt. } \%)\end{array}$ & & \\
\hline HE-ALEX-50-T45 & $\begin{array}{l}\text { High-energy MA, } \\
\text { ALEX-50 (55 wt.\%) + } \\
\text { PTFE (45 wt. } \%)\end{array}$ & & \\
\hline
\end{tabular}

Table 2. $T_{f l}$ for $\mathrm{Al}$ reaction with different fluoropolymers and ammonium perchlorate (AP) as a function of the oxidizer mass fraction in the composite (NASA Chemical Equilibrium with Applications (CEA) software, $\left.p_{c}=1.0 \mathrm{MPa}\right)$.

\begin{tabular}{cccccc}
\hline Oxidizer & Density, $\mathbf{k g} / \mathbf{m}^{\mathbf{3}}$ & $\mathbf{1 0}$ wt.\% & $\mathbf{1 5}$ wt.\% & $\mathbf{3 0}$ wt.\% & $\mathbf{4 5}$ wt.\% \\
\hline AP & 1950 & $1754 \mathrm{~K}$ & $2327 \mathrm{~K}$ & $2656 \mathrm{~K}$ & $3524 \mathrm{~K}$ \\
VFHFP & 1800 & $933.6 \mathrm{~K}$ & $1304 \mathrm{~K}$ & $1752 \mathrm{~K}$ & $1975 \mathrm{~K}$ \\
PTFE & 2200 & $1013 \mathrm{~K}$ & $1440 \mathrm{~K}$ & $1853 \mathrm{~K}$ & $2095 \mathrm{~K}$ \\
\hline
\end{tabular}


Air-passivated ALEX powders with nominal sizes of $100 \mathrm{~nm}$ and $50 \mathrm{~nm}$ were considered in the study. The nominal coating mass fraction was $10 \%$ for all the coated powders but AP15-ALEX-100B (see Table 1). Production details for the starting $\mathrm{nAl}$ powders and for the variants coated by stearic acid and fluoropolymer are reported elsewhere [40]. The AP15-ALEX-100B was produced by dispersing $\mathrm{nAl}$ in an acetone solution of AP. The ingredients were mixed during ultrasound irradiation of the bath. Solvent was gradually removed by evaporation at $318 \mathrm{~K}$. Powders were dried for $72 \mathrm{~h}$ in an oven at $333 \mathrm{~K}$ before grinding. Activated powders were produced by low-energy (LE) and high-energy (HE) mechanical activation (MA) processes, both developed at SPLab. Details on the former process are provided in dedicated works [24,48], while the latter procedure is undergoing patenting. Mechanical activation enables the coupling of different materials, removing some of the limitations of other techniques, such as the chemical compatibility required for efficient coating.

\subsection{Tested Formulations}

Tested fuel formulations are reported in Table 3. Relative ballistic grading was performed considering a non-metallized HTPB baseline (for formulation details, see Reference [63]). The investigated compositions were all produced at lab-scale level. Formulations F2 to F7 featured a $10 \mathrm{wt} . \%$ load of $\mathrm{Al}$ powders, and they were produced by a special manufacturing procedure aiming at inter-particle cold-cohesion mitigation (i.e., ultrasound irradiation [41-43]). The solid fuel compositions from F8 to F14 featured the same metal molar content as F2, and they were prepared without special procedures for the additive dispersion in the matrix. The effects of the addition to the HTPB binder of PTFE and of (separated) Al and PTFE powders were investigated using F15 and F16. High-energy mechanical milling was used to produce the additives tested in the fuel formulations with the highest metal mass fractions (F17 to F19), which were designed to explore the possibility of significantly augmented $\dot{m}_{f}$ using high loads of Al-based composites with PTFE. Fuels F16 to F18 were formulated granting the same HTPB to PTFE ratio as the F15. Actual fuel densities were evaluated by a high-precision balance measuring sample dry weight and buoyancy. For all the tested fuel formulations, the difference between the actual density and the theoretical maximum density (TMD) was lower than $3 \%$.

Table 3. Tested fuel formulations: nomenclature, composition, and details. ID: identifier; HTPB: hydroxyl-terminated polybutadiene; TMD: theoretical maximum density.

\begin{tabular}{|c|c|c|c|c|}
\hline Solid Fuel ID & HTPB, wt. $\%$ & Energetic Additive ID, wt. $\%$ & TMD, kg/m ${ }^{3}$ & Notes \\
\hline F1 & 100 & - & 920 & Relative grading baseline \\
\hline $\mathrm{F} 2$ & 90.0 & $\mu \mathrm{Al} 15,10.0$ & 980 & 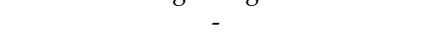 \\
\hline F3 & 90.0 & $\mu \mathrm{Al} 17.5,10.0$ & 980 & - \\
\hline $\mathrm{F} 4$ & 88.0 & ALEX-100, 10.0 & 992 & \multirow{4}{*}{$\begin{array}{l}\text { Formulation includes } 2 \text { wt. } \% C B, \\
\text { additive dispersion by ultrasound } \\
\text { irradiation during mixing }\end{array}$} \\
\hline F5 & 88.0 & L-ALEX-100, 10.0 & 992 & \\
\hline F6 & 88.0 & VF-ALEX-100F, 10.0 & 992 & \\
\hline F7 & 88.0 & VF-ALEX-50E, 10.0 & 992 & \\
\hline F8 & 88.7 & ALEX-100B, 11.3 & 906 & \multirow{7}{*}{$\begin{array}{l}\text { Formulation } \mathrm{Al} \text { content is equimolar } \\
\text { to } \mathrm{F} 2 \text {, no additive dispersion by } \\
\text { ultrasound irradiation during mixing }\end{array}$} \\
\hline F9 & 87.4 & AP $1.9 \%+$ ALEX-100B $10.7 \%$ a & 999 & \\
\hline F10 & 87.4 & AP15-ALEX-100B, 12.6 & 999 & \\
\hline F11 & 89.9 & LE- $\mu \mathrm{Al} 15,10.1$ & 980 & \\
\hline F12 & 89.0 & LE- $\mu$ Al15-T10, 11.0 & 986 & \\
\hline F13 & 85.5 & LE- $\mu$ Al15-T30, 14.5 & 986 & \\
\hline F14 & 84.9 & LE- $\mu$ Al7.5-T30, 15.1 & 1006 & \\
\hline F15 & 65.0 & PTFE, 35.0 & 1150 & Evaluation of HTPB + PTFE ballistics \\
\hline \multirow[b]{2}{*}{ F16 } & \multirow[b]{2}{*}{45.5} & PTFE, 24.5 & & \multirow{2}{*}{$\begin{array}{l}\text { Evaluation of the effects of HTPB + } \\
\text { PTFE on nAl combustion (no } \\
\text { mechanical activation) }\end{array}$} \\
\hline & & ALEX-50, 30.0 & 1389 & \\
\hline F17 & 45.5 & HE- $\mu$ Al15-T45, 54.5 & 1389 & \multirow{3}{*}{$\begin{array}{l}\text { HE activation effects evaluation with } \\
\text { respect to LE, increased PTFE content }\end{array}$} \\
\hline F18 & 45.5 & HE-ALEX-50-T45, 54.5 & 1389 & \\
\hline F19 & 30.0 & HE-ALEX-50-T45, 70.0 & 1630 & \\
\hline
\end{tabular}

${ }^{a}$ Fuel formulation prepared to provide the same nominal composition of F10. 


\section{Experimental Methods}

\subsection{Aluminum and Aluminum-Based Additives Pre-Burning Characterization}

The pre-burning characterization of the metal additives included particle size distribution (PSD) by laser diffraction (Malvern Mastersizer 2000 with dry/liquid dispersion unit for micron- and nano-sized particles, respectively), SSA determination by $\mathrm{N}_{2}$ adsorption/desorption, scanning electron microscopy (SEM), transmission electron microscopy (TEM), and transmission energy dispersion (TED) imaging. The $C_{A l}$ of the powders was determined by $\mathrm{Al}+\mathrm{H}_{2} \mathrm{O}$ reaction in a basic solution $(10$ wt. $\% \mathrm{NaOH})$ The reactivity of the powders was investigated by slow heating rate thermogravimetry (TG). The TG relative grading of the additives was performed in air, at $10 \mathrm{~K} / \mathrm{min}$, considering the reactivity parameters identified by Ilyin et al. [34]. The reactivity data evaluated on the TG trace are illustrated in Figure 1. The $\mathrm{Al} \rightarrow \mathrm{Al}_{2} \mathrm{O}_{3}$ conversion factor was evaluated as follows:

$$
\alpha(T)=\frac{\Delta m(T)}{0.89 \cdot C_{A l}} .
$$

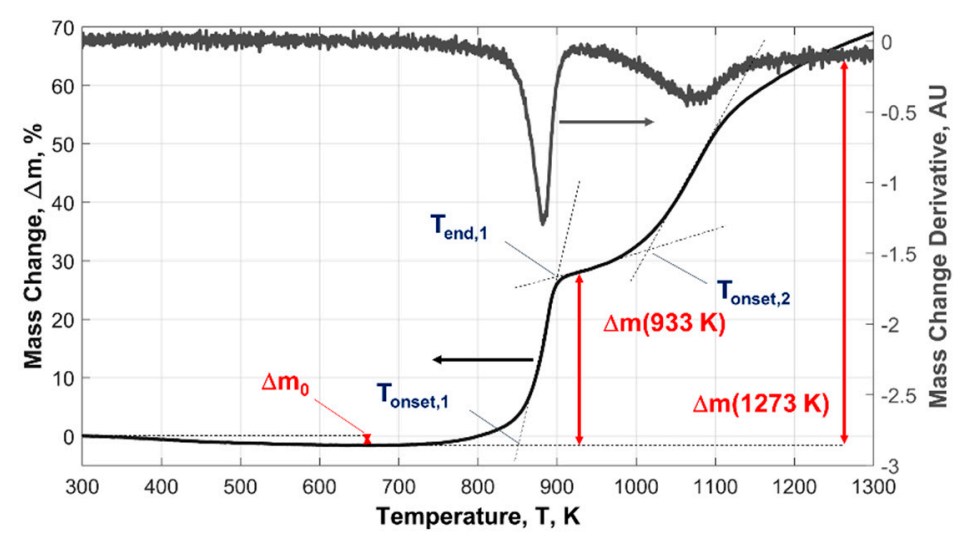

Figure 1. Reactivity parameters for thermogravimetry (TG) analysis [34]. The determination of onset and end points was performed based on the differential TG (DTG) curve. Percent mass change was evaluated with respect to the initial mass of the specimen.

\subsection{Burning Behavior Investigation}

\subsubsection{Lab-Scale Two-Dimensional (2D) Radial Micro-Burner}

The SPLab research team designed and developed a 2D radial burner for the relative ballistic grading of solid fuel formulations at the lab-scale level. Cylindrical-shaped fuel grains with a length of $30 \mathrm{~mm}$, outer case diameter of $20 \mathrm{~mm}$, and central port diameter $\left(D_{0}\right)$ of $4 \mathrm{~mm}$ are typically tested. The SPLab facility features peculiar characteristics such as the visualization of the burning specimen head-end, and a quasi-steady $p_{c}$ during the combustion [63]. In the 2D radial burner, the $p_{c}(t)$ is monitored by a piezo-resistive pressure transducer and controlled by a pressure regulator commanding exhaust electro-valves. These servo-actuators are opened/closed depending on the sensed pressure difference between actual and threshold values. The latter was selected for the test (and it could be easily changed between different runs, if needed). The $\dot{m}_{o x}(t)$ was monitored and controlled by a digital flowmeter. The $\dot{m}_{o x}(t)$ and the $p_{c}(t)$ could be controlled independently. Oxidizer injection was performed by standard (non-swirled) flow. Tested strand ignition was achieved by a primer charge whose combustion was initiated by a laser beam impinging on it. A scheme of the experimental set-up is shown in Figure 2, while its peculiarities were discussed elsewhere [63]. In the current study, gaseous oxygen (GOX) was taken as the oxidizer, and combustion tests were performed with $\dot{m}_{o x}$ of $5 \mathrm{~g} / \mathrm{s}$ and 6 $\mathrm{g} / \mathrm{s}$ (the two operating conditions were identified as $\mathrm{A}$ and $\mathrm{B}$, respectively), with $p_{c}=1.0 \mathrm{MPa}$. 


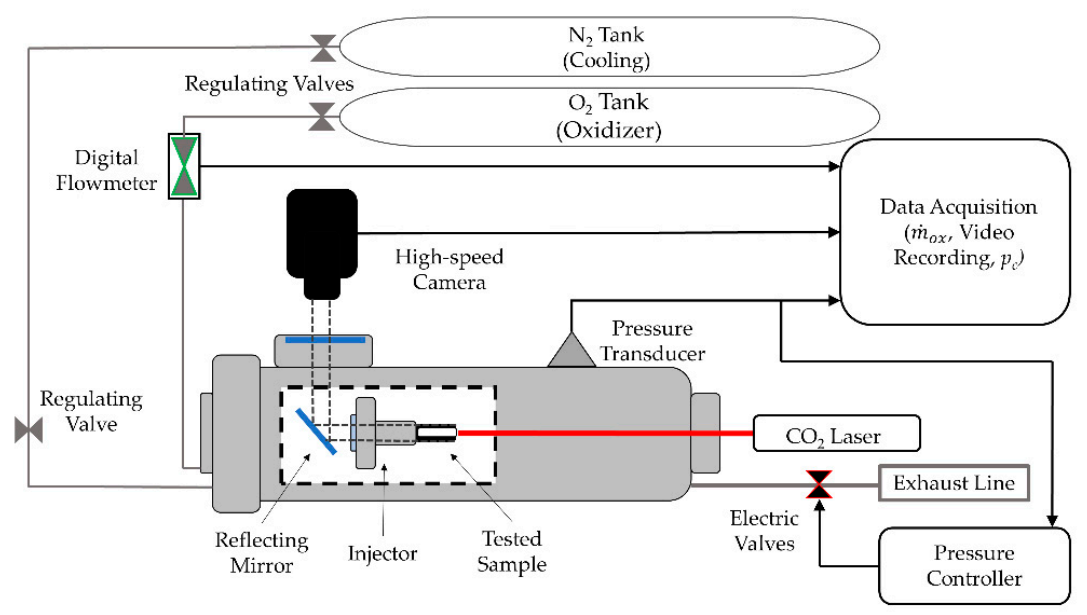

Figure 2. Lab-scale two-dimensional (2D) radial burner scheme.

\subsubsection{Time-Resolved Regression Rate}

An optical, time-resolved technique for $r_{f}$ measurement was developed and validated at SPLab [16, 53,63]. The time-resolved $r_{f}$ was evaluated by central port diameter sampling during the combustion (see Figure 3). Regression surface tracking started from the frame when the head-end central port diameter became visible (after primer charge ignition). Data sampling extended until the end of the combustion (depending on visualization quality). Diameter sampling was performed with the maximum possible frequency $(5-20 \mathrm{~Hz}$ under the investigated conditions, with higher frequencies in the earlier phases of the burning process). During the combustion, central port diameter was sampled along different radial directions (depending on combustion uniformity). The local diameters were averaged to provide $\bar{D}_{i}$. This diameter was considered uniform for the whole specimen length. The $\bar{D}_{i}\left(t_{i}\right)$ was a discrete information in time, which was successively fitted to achieve a continuous $\bar{D}(t)$, as shown in Equation (2).

$$
\bar{D}(t)-D_{0}=a_{D} \cdot\left(t-t_{0}\right)^{n_{D}}, t \geq t_{i g n}>t_{0}=0
$$

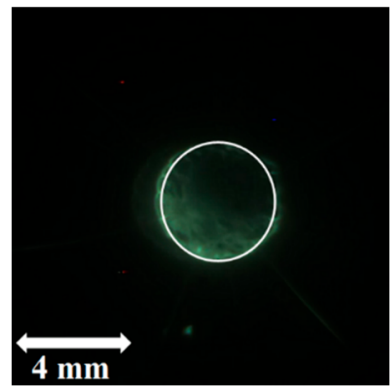

(a) $t_{i g n}$

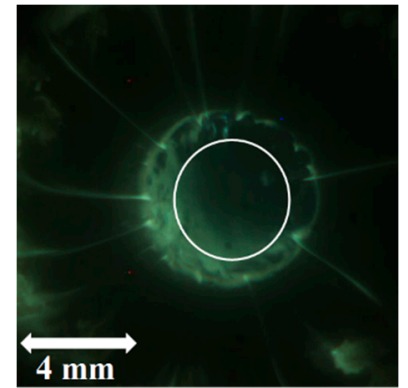

(b) $t_{i g n}+1 \mathrm{~s}$

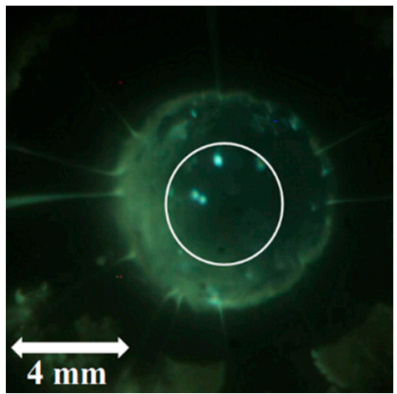

(c) $t_{i g n}+2 \mathrm{~s}$

Figure 3. Typical head-end visualization of a combustion run in the $2 \mathrm{D}$ radial burner (F3-GOX, $p_{c}=1.0$ $\mathrm{MPa}$ : (a) sample ignition, $(\mathbf{b}, \mathbf{c})$ central port diameter enlargement in time due to solid fuel regression (the initial port diameter $\left(D_{0}\right)$ is highlighted by the white circle).

In time-resolved techniques, the function describing the diameter evolution in time was valid starting from $t_{i g n}$. The latter parameter was ad hoc defined as the one enabling the maximization of the data fitting $\left(R^{2}\right)$ of the $\bar{D}(t)-D_{0}$ based on $a_{D}$ and $n_{D}$ (Equation (2)). In the implemented technique, the $t_{\text {ign }}$ values were in agreement with convective ignition time estimated by open literature models, as discussed in References [53,63]. The ballistic data of a fuel formulation tested under the selected conditions were determined starting from Equation (2) [63]. The time derivative of the $\bar{D}(t)-D_{0}$ 
provided the $r_{f}(t)$, while the $G_{o x}(t)$ could be determined from the diameter history once the operating condition (and, in particular, $\left.\dot{m}_{o x}\right)$ was defined [63]. The $r_{f}\left(G_{o x}\right)$ history in time was approximated by a power law as follows:

$$
r_{f}\left(G_{o x}\right)=a_{r} G_{o x}^{n_{r}}(t), t \geq t_{i g n}>t_{0} .
$$

The $r_{f}(t)$ and the $\bar{D}(t)$ were used to evaluate the mass burning rate.

$$
\dot{m}_{f}(t)=\rho_{f}\left[\pi \bar{D}(t) L_{f}\right] r_{f}(t), t \geq t_{i g n}>t_{0} .
$$

Time-resolved data could be used to determine the time-averaged ballistics of the investigated formulation [63]. In particular, the time-averaged values of the $r_{f}$ and of the $G_{o x}$ were evaluated as follows:

$$
\begin{gathered}
\left\langle r_{f}(t)\right\rangle=\frac{1}{t-t_{i g n}} \int_{t_{i g n}}^{t} r_{f}(t) d t, t_{\text {end }} \geq t \geq t_{\text {ign }}>t_{0} . \\
\left\langle G_{o x}(t)\right\rangle=\frac{1}{t-t_{i g n}} \int_{t_{i g n}}^{t} G_{o x}(t) d t, t_{\text {end }} \geq t \geq t_{\text {ign }}>t_{0} .
\end{gathered}
$$

As extensively discussed in References [16,63], Equations (5) and (6) can be used to compare the overall time-averaged data derived from Equation (2) to thickness over time (TOT) results of a test. The typical experimental output obtained by this data reduction technique is shown in Figure 4, where time-resolved instantaneous and time-averaged data for a HTPB-GOX run are reported and compared with the corresponding TOT-based $r_{f}$ and $G_{o x}$, which were defined as follows:

$$
\begin{gathered}
\left\langle r_{f}\right\rangle_{T O T}=\frac{1}{2} \frac{\bar{D}\left(t_{\text {end }}\right)-\bar{D}\left(t_{\text {ign }}\right)}{t_{\text {end }}-t_{\text {ign }}}, t_{\text {end }}>t_{\text {ign }}>t_{0} . \\
\left\langle G_{O x}\right\rangle_{T O T}=\frac{4 \dot{m}_{o x}}{\pi\left[\frac{\bar{D}\left(t_{\text {end }}\right)+\bar{D}\left(t_{\text {ign }}\right)}{2}\right]^{2}}, t_{\text {end }}>t_{\text {ign }}>t_{0}
\end{gathered}
$$

Equations (5) and (6) and the TOT data typically show percent differences of less than $5 \%$ (see References $[16,63]$ for details). Under the investigated conditions, the time-averaged and the instantaneous data featured minor differences at a given oxidizer mass flux (see Figure 4).

For a given experimental condition $\left(D_{0}, \dot{m}_{o x}\right.$, and $\left.p_{c}\right)$, single tests for the same fuel formulation yielded the definition of ensemble average curves, enabling the relative grading of the different compositions $[16,63]$. Ensemble average curves were completed by error bars considering the data dispersion of the performed combustion tests. Single-test diameter histories resulting from the application of Equation (2) were fitted together in the ensemble curve of the same kind. The resulting $\bar{D}(t)-D_{0}$ was then used to determine the relevant ballistic parameters. Thus, following the same logical steps performed on a single test, $r_{f}\left(G_{o x}\right)$ and $\dot{m}_{f}\left(G_{o x}\right)$ could be evaluated. The uncertainties on the ensemble average curve were evaluated by considering confidence intervals with $95 \%$ accuracy. A minimum of three tests were considered for error bar definition. 


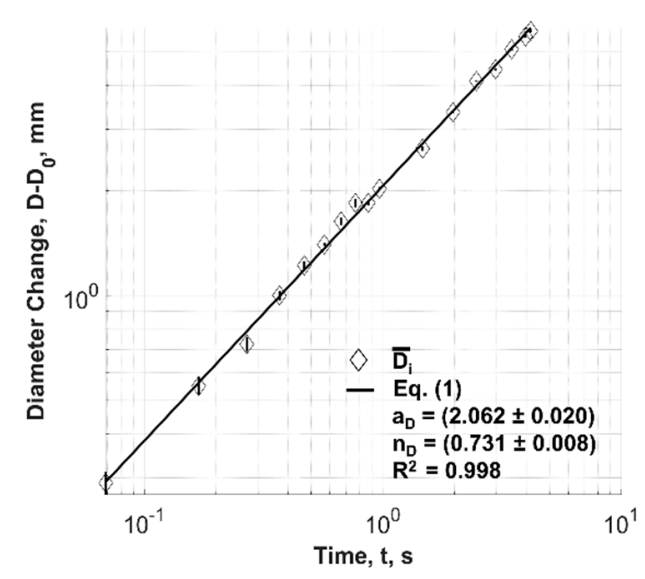

(a)

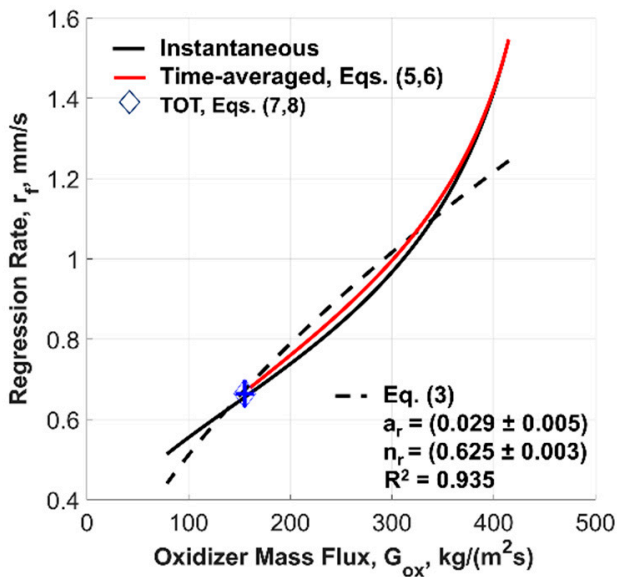

(b)

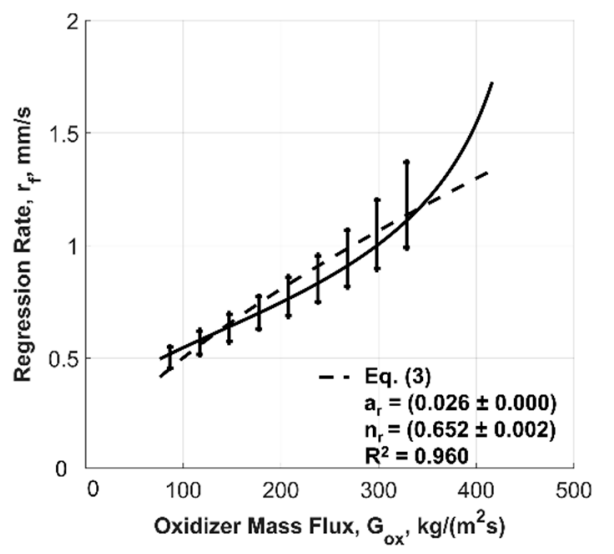

(c)

Figure 4. Time-resolved regression rate determination (HTPB-GOX, $\left.p_{c}=1.0 \mathrm{MPa}, \dot{m}_{o x}=6 \mathrm{~g} / \mathrm{s}\right)$ : (a) sampled diameter interpolation in time (Equation (1)), (b) instantaneous $r_{f}\left(G_{0 x}\right)$ with its power law approximation (Equation (3)), time-averaged history (Equations (5) and (6)), and thickness over time (TOT) data, (c) ensemble average data with error bars.

\subsubsection{Lab-Scale Micro-Slab Motor}

Combustion surface visualizations were performed in a windowed micro-slab burner $[17,84]$. The implemented set-up featured the same general layout as the radial burner shown in Figure 2. Burning fuel strand images were captured by side-window. Recorded images showed the solid fuel slab and the flame zone. A typical combustion frame is shown in Figure 5. The burning strands had a length of $15 \mathrm{~mm}$ and a square cross section of $3 \times 3 \mathrm{~mm}$. The ignition of the samples was achieved by a non-aluminized propellant primer charge (in turn ignited by a hot wire). The facility enabled the exploration of different $p_{c}$ by changing the throat area of the implemented nozzle. The burning surface visualization runs were intended to provide qualitative insight into the phenomena involved in the combustion of metallized fuel formulations, while no detailed quantitative information could be captured by these tests. The visualizations were performed in GOX, with $p_{c}=0.4 \mathrm{MPa}$, and 145 $\mathrm{kg} /\left(\mathrm{m}^{2} \cdot \mathrm{s}\right) \leq G_{o x} \leq 160 \mathrm{~kg} /\left(\mathrm{m}^{2} \cdot \mathrm{s}\right)$. The frame rate of the captured videos was in the range 5000-10,000 frames per second (fps), depending on the investigated fuel $r_{f}$ and observable phenomena. 


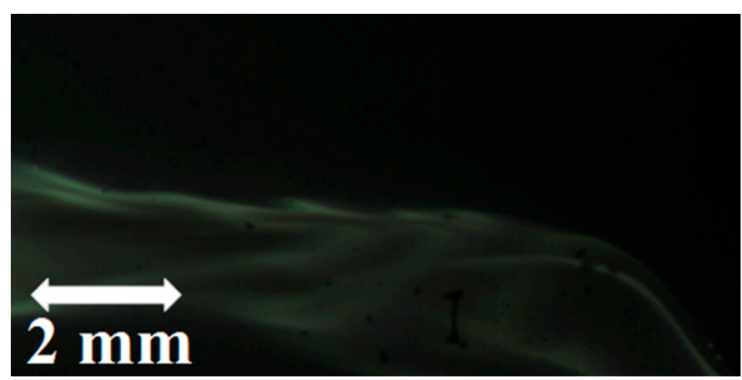

Figure 5. Combustion visualization with slab configuration (F1-GOX, $p_{c}=0.4 \mathrm{MPa}$ ). The oxidizer flows from right to left. Note the diffusion flame over the solid fuel grain.

\section{Experimental Results and Discussion}

\subsection{Additives Pre-Burning Characterization}

The PSD, SSA, and $C_{A l}$ data for the tested additives are reported in Table 4. Selected SEM and TED images of the additives are shown in Figure 6. Slow heating rate reactivity parameters from the TG tests are reported in the Table 5. In this work, the implemented LE and HE activation procedures aimed at reducing the diffusion distance between the PTFE and the Al. When considering metal-loaded fuel formulations for hybrid rocket applications, the pursued effects of additives are increased $r_{f}$ and $\dot{m}_{f}$. The achievement of enhanced ballistic performance requires materials with fast reactivity, while additive metal content exerts limited effects on performance (particularly when $\mathrm{O}_{2}$ is used as oxidizer) [25].

Table 4. Particle size distribution (PSD), specific surface area (SSA), and $C_{A l}$ data for the tested additives, AP, and PTFE.

\begin{tabular}{|c|c|c|c|c|c|c|}
\hline Powder ID & $D_{43}, \mu \mathrm{m}$ & $D_{(0.1)}, \mu \mathrm{m}$ & $D_{(0.5)}, \mu \mathrm{m}$ & $D_{(0.9)}, \mu \mathrm{m}$ & $\mathrm{SSA}, \mathrm{m}^{2} / \mathrm{g}$ & $C_{A l}$, wt. $\%$ \\
\hline$\mu \mathrm{Al} 15$ & 19.8 & 10.0 & 17.9 & 32.3 & $<0.1$ & $99.5 \pm 0.4$ \\
\hline$\mu \mathrm{Al} 7.5$ & 6.6 & 2.99 & 6.08 & 11.0 & $<0.1$ & $95.3 \pm 0.2$ \\
\hline ALEX-100 & 0.138 & 0.105 & 0.135 & 0.176 & $11.8 \pm 0.4$ & $89.0 \pm 5.0$ \\
\hline ALEX-50 & - & - & - & - & $15.5 \pm 0.1$ & $86.3 \pm 4.1$ \\
\hline ALEX-100B & 0.141 & 0.104 & 0.138 & 0.182 & $11.3 \pm 0.1$ & $88.0 \pm 1.5$ \\
\hline L-ALEX-100 & - & - & - & - & $9.1 \pm 0.3$ & $70.3 \pm 4.3^{\mathrm{a}}$ \\
\hline VF-ALEX-100F & - & - & - & - & $6.9 \pm 0.2$ & $78.3 \pm 4.4$ \\
\hline VF-ALEX-50E & - & - & - & - & $10.9 \pm 0.3$ & $78.4 \pm 4.4$ \\
\hline AP15-ALEX-100B & 6.73 & 0.42 & 1.66 & 16.0 & - & $76.0 \pm 1.3$ \\
\hline LE- $\mu$ Al15 & 123 & 15.9 & 90.8 & 284 & $<1.0$ & $98.2 \pm 0.1$ \\
\hline LE- $\mu$ Al15-T10 & 28.4 & 12.0 & 25.1 & 49.5 & $<1.0$ & $90.5 \pm 0.1$ \\
\hline LE- $\mu$ Al15-T30 & 31.2 & 5.46 & 21.7 & 59.4 & $<1.0$ & $68.6 \pm 0.6$ \\
\hline LE- $\mu$ Al7.5-T30 & 13.5 & 2.67 & 8.13 & 29.2 & $<1.0$ & $65.8 \pm 0.4$ \\
\hline HE- $\mu$ Al15-T45 & 52.2 & 4.05 & 22.6 & 141 & $1.5 \pm 0.1$ & $53.7 \pm 1.2$ \\
\hline HE-ALEX-50-T45 & 85.2 & 3.41 & 41.7 & 237 & $5.9 \pm 0.1$ & $47.3 \pm 1.7$ \\
\hline $\mathrm{AP}$ & 10.2 & 0.68 & 5.74 & 26.4 & - & - \\
\hline PTFE & 7.24 & 0.36 & 0.88 & 8.28 & - & - \\
\hline
\end{tabular}

${ }^{\text {a }}$ Active metal content underestimation due to side-effects in the $\mathrm{Al}+\mathrm{H}_{2} \mathrm{O}$ reaction [40]. 


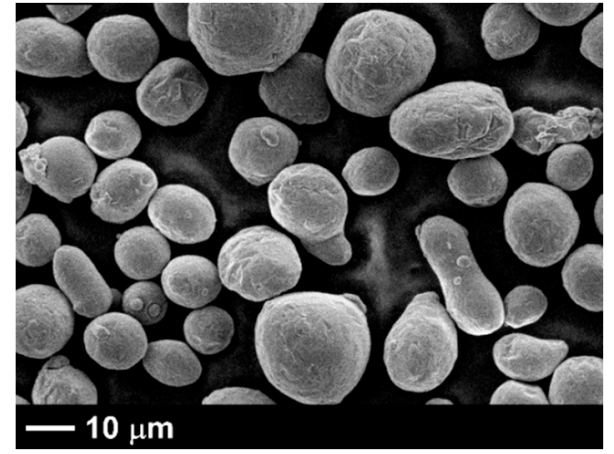

(a)

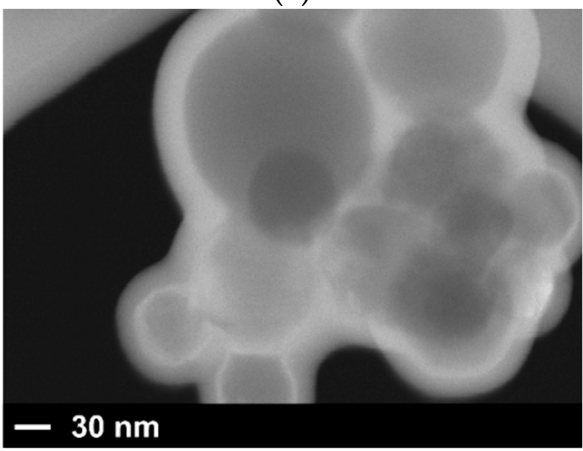

(c)

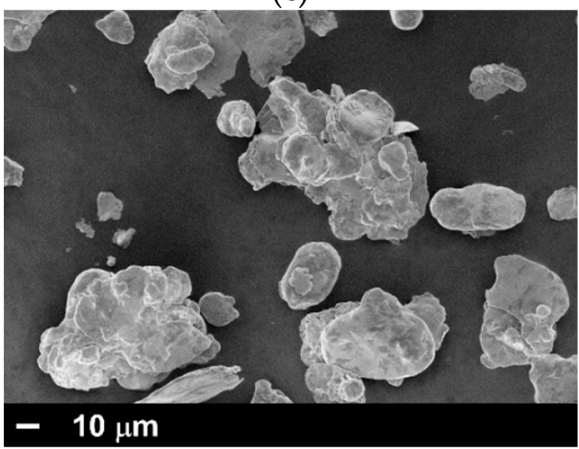

(e)

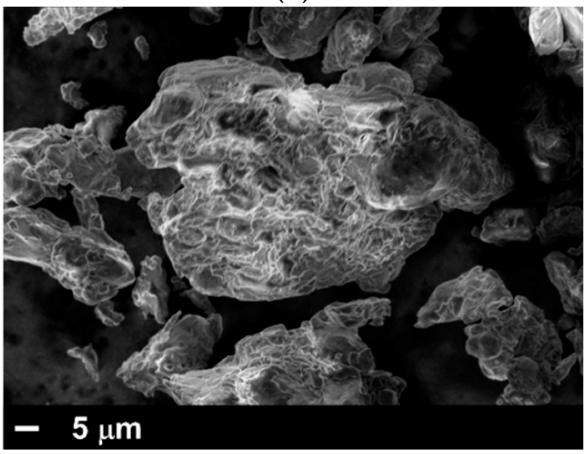

(g)

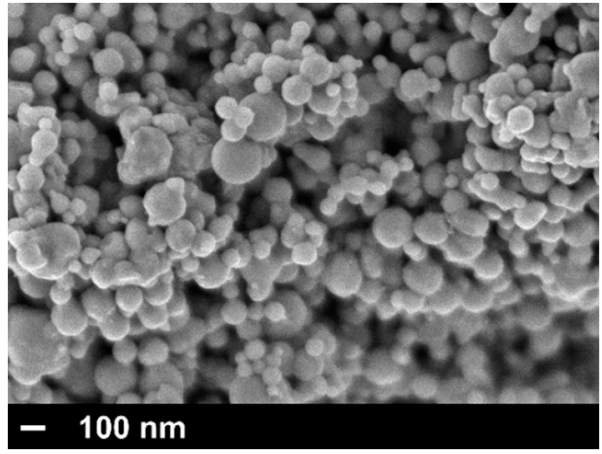

(b)

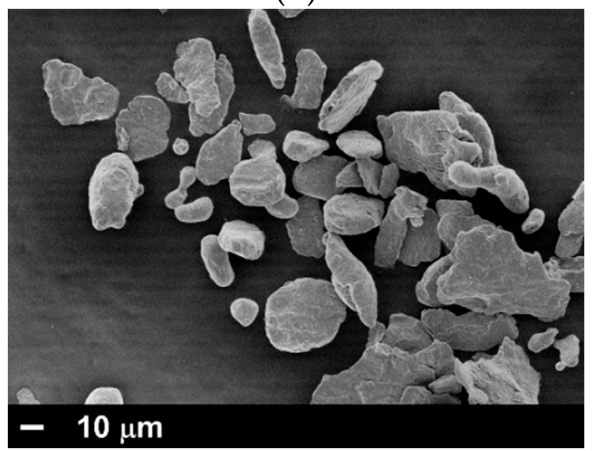

(d)

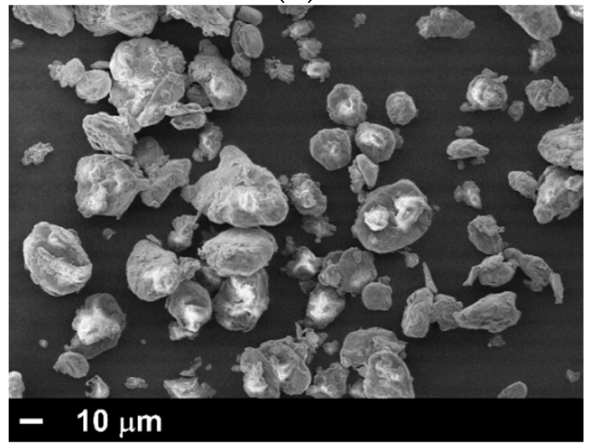

(f)

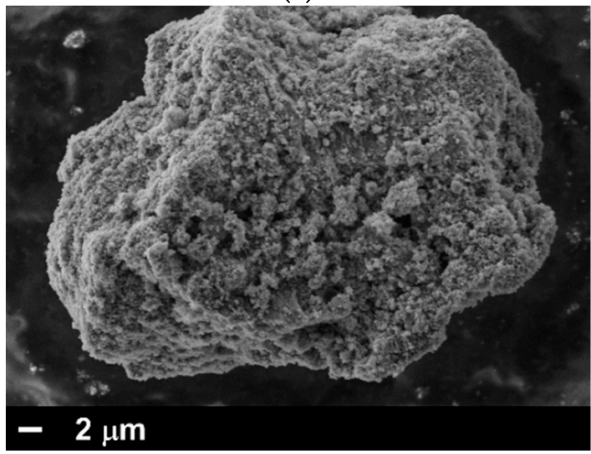

(h)

Figure 6. Electron microscopy images of the investigated powders: (a) SEM of $\mu$ Al15, (b) SEM of ALEX-100, (c) transmission energy dispersion (TED) of VF-ALEX-100F, (d) SEM of LE- $\mu$ Al15, (e) SEM of LE- $\mu$ Al15-T10, (f) SEM of LE- $\mu$ Al15-T30, (g) SEM of HE- $\mu$ Al15-T45, and (h) SEM of HE-ALEX-50-T45.

The $\mu \mathrm{Al15}$ featured spherical/spheroid particles, with (apparent) smooth texture (see Figure 6a). The PSD data reported in Table 4 show a monomodal distribution of the measured diameters. The powder showed a limited reactivity under slow heating rates $(\alpha(933 \mathrm{~K})=1.1 \%, \alpha(1273 \mathrm{~K})=8 \%)$ due to the low SSA. The $\mu$ Al7.5 featured a small volumetric fraction of sub-micrometric particles $(\sim 2 \%)$, as 
testified by the low $D_{(0.1)}$ reported in Table 4 . The TG reactivity of the powder was similar to the one of the coarser counterpart (see Table 5). In spite of the SSA difference (see Table 4), ALEX-100 and ALEX-50 exhibited similar $T_{\text {on,1 }}$. ALEX-50 showed the highest $\alpha(933 \mathrm{~K})$ and $\alpha(1273 \mathrm{~K})$ in the dataset. The pyrocatechol-coated powder showed no marked SSA and reactivity differences with respect to the ALEX-100 (see Tables 4 and 5). This was due to the reduced coating mass fraction (0.2 wt.\%), limiting coating-related effects such as particle clustering. Other coated powders featured higher SSA reduction (i.e., particle size increase) due to coating gluing of originally separated particles and because of cluster coverage by coating deposition. The AP15-ALEX-100B showed micron-sized particles that were clusters of the original ALEX-100B glued and (at least partially) covered by AP. Fluoropolymer coating reduced the reactivity of the powders at slow heating rates, yielding increased $T_{\text {on,1 }}$ and lowered $\alpha(1273 \mathrm{~K})$. This was probably induced by carbonaceous residuals from coating degradation that partially shielded the particles from oxidation. The effect was lowered for VF-ALEX-50E, which was prepared from a powder featuring higher reactivity than the 100-nm counterpart. In spite of the composition differences between the hydrocarbon coating and the AP composite, AP15-ALEX-100B and the L-ALEX-100 showed nearly the same reactivity as the original powders, due to the degradation behavior of their surface layers featuring vaporization/sublimation for temperatures $<670 \mathrm{~K}$.

Table 5. Powder reactivity: slow heating rate thermogravimetric (TG) data (air, $10 \mathrm{~K} / \mathrm{min}, 0.1 \mathrm{MPa}$ ).

\begin{tabular}{|c|c|c|c|c|c|}
\hline Powder ID & $\Delta m_{0}$, wt. $\%$ & $T_{o n, 1}, \mathrm{~K}$ & $\alpha(933 \mathrm{~K}), \%$ & $T_{o n, 2}, \mathrm{~K}$ & $\alpha(1273 \mathrm{~K}), \%$ \\
\hline$\mu \mathrm{Al15}$ & -0.1 & 845 & 1.1 & 1173 & 8.0 \\
\hline$\mu \mathrm{Al} 7.5$ & -0.2 & 843 & 2.2 & 1203 & 13.7 \\
\hline ALEX-100 & -1.0 & 850 & 40.4 & 983.2 & 83.3 \\
\hline ALEX-50 & -1.0 & 850 & 52.1 & 1000 & 90.9 \\
\hline ALEX-100B & -1.3 & - & 36.3 & - & $79.3^{\mathrm{a}}$ \\
\hline L-ALEX-100 & -3.1 & 858 & $45.1^{b}$ & 985.0 & $103.5^{b}$ \\
\hline VF-ALEX-100F & -5.8 & 888 & 33.9 & 1088 & 76.8 \\
\hline VF-ALEX-50E & -5.1 & 883 & 39.4 & 1091 & 88.5 \\
\hline AP15-ALEX-100B & -12.3 & 858 & 39.8 & 993.0 & 84.0 \\
\hline LE- $\mu \mathrm{Al15}$ & -0.1 & 831 & 3.9 & 1198 & 14.5 \\
\hline LE- $\mu$ Al15-T10 & -7.1 & 899 & 2.5 & 1216 & 18.1 \\
\hline LE- $\mu$ Al15-T30 & -24.1 & 902 & 0.8 & 1175 & 9.8 \\
\hline LE- $\mu \mathrm{Al} 7.5-\mathrm{T} 30$ & -26.7 & 902 & 1.7 & 1174 & 41.0 \\
\hline HE- $\mu$ Al15-T45 & -36.5 & 1148 & 0.0 & - & 27.4 \\
\hline HE-ALEX-50-T45 & -34.2 & 893 & 43.0 & 988 & $61.0^{\mathrm{a}}$ \\
\hline
\end{tabular}

a Limiting temperature of $1223 \mathrm{~K} .^{\mathrm{b}}$ Active metal content underestimation due to side-effects in the $\mathrm{Al}+\mathrm{H}_{2} \mathrm{O}$ reaction [40].

The non-isothermal oxidation of LE- $\mu$ Al15 showed an anticipated $T_{\text {on,1 }}$ and higher $\alpha$ (933 K) and $\alpha(1273 \mathrm{~K})$ than the original micron-sized powder. Activated powders derived from $\mu \mathrm{Al} 15$ showed irregular shape and texture (Figure 6e,f). PTFE friction and wearing properties were the likely explanation for the size reduction of these powders with respect to LE- $\mu$ Al15 (see Table 4) [88]. The PTFE-based composites showed $C_{A l}$ decrease with respect to $\mu$ Al15. The metal content reduction was $9 \% \pm 1 \%$ for LE- $\mu$ Al15-T10 and $31 \% \pm 1 \%$ for LE- $\mu$ Al15-T30 and LE- $\mu$ Al7.5-T30. The $\Delta m_{0}$ data of Table 5 show a general agreement with these values, thus confirming the quality of the produced powders. All the LE-activated powders featured SSA $<1 \mathrm{~m}^{2} / \mathrm{g}$. The SEM images of LE- $\mu$ Al15 showed flake particles with limited surface roughness, and the presence of some spheroid particles due to the low-energy process (Figure 6d). The laser diffraction measurement showed an increase in the particle size (see Table 4). The PSD data were evaluated considering spherical and smooth-texture particles (Malvern Mastersizer 2000 data reduction algorithm); thus, considering the flake morphology of mechanically activated particles (Figure $6 \mathrm{~d}-\mathrm{h}$ ) achieved results should be considered for the relative grading of milled particles only. LE- $\mu$ Al15 showed a reduced $C_{A l}$ with respect to $\mu$ Al15 due to the crack-healing of the alumina shell during the activation process. The activation volume was filled with air; thus, the $\mathrm{Al}_{2} \mathrm{O}_{3}$ shell ruptures induced by the mechanical stresses yielded $\mathrm{Al}$ core exposure and oxidation with consequent $C_{A l}$ reduction. The oxidation onset of the LE PTFE-containing composites 
occurred at higher temperatures with respect to $\mu$ Al15 and LE-Al15. Under the investigated conditions, LE- $\mu$ Al7.5-T30 was the LE-activated composite featuring the highest $\alpha(\mathrm{T})$. This result was probably due to the reduced particle size of the initial powder, in turn yielding a final product with reduced $D_{43}$ and $D_{0.5}$ with respect to other $\mu$ Al15-based composites. Both HE-activated composites featured increased SSA with respect to the LE-activated powders, as shown in Table 4. HE- $\mu$ Al15-T45 showed particles with rough texture and irregular shape (see Figure $6 \mathrm{~g}$ ). The HE-ALEX-50-T45 SSA reduction with respect to the original ALEX was due to the creation of nAl + PTFE granules with a complex structure but increased size (see Figure $6 \mathrm{~h}$ ). Data for $\mathrm{Al} \rightarrow \mathrm{Al}_{2} \mathrm{O}_{3}$ conversion of the two powders showed $\alpha$ (1273 $\mathrm{K})=27.5 \%$ for the $\mu \mathrm{Al15}$-based composite, and $\alpha(1223 \mathrm{~K})=61.0 \%$ for HE-ALEX-50-T45.

\subsection{Burning Behavior}

\subsubsection{Time-Resolved Regression Rate}

Relative ballistic grading results are reported in Figures 7 and 8 and Table 6 . All the ballistic data were defined by ensemble average curves summarizing, at least four tests per formulation. All the fuels but F3, F8-F10, and F15-F19 were tested with $\dot{m}_{0 x} .=5 \mathrm{~g} / \mathrm{s}$; thus, their performance was evaluated taking F1A as baseline. For the tests with $\dot{m}_{o x}=6 \mathrm{~g} / \mathrm{s}, \mathrm{F} 1 \mathrm{~B}$ was considered as the reference for the relative grading. Data reported in Table 6 feature relatively low $R^{2}$ due to the typical trend captured by time-resolved approaches, as originally reported by Evans et al. [18] (see Figure 4b,c). The time-averaged data of Figure 8 were evaluated using Equations (5) and (6) at $\left\langle G_{o x}\right\rangle=(250 \pm 15)$ $\mathrm{kg} /\left(\mathrm{m}^{2} \cdot \mathrm{s}\right)$. The latter value was selected since it was common to all the tested formulations.

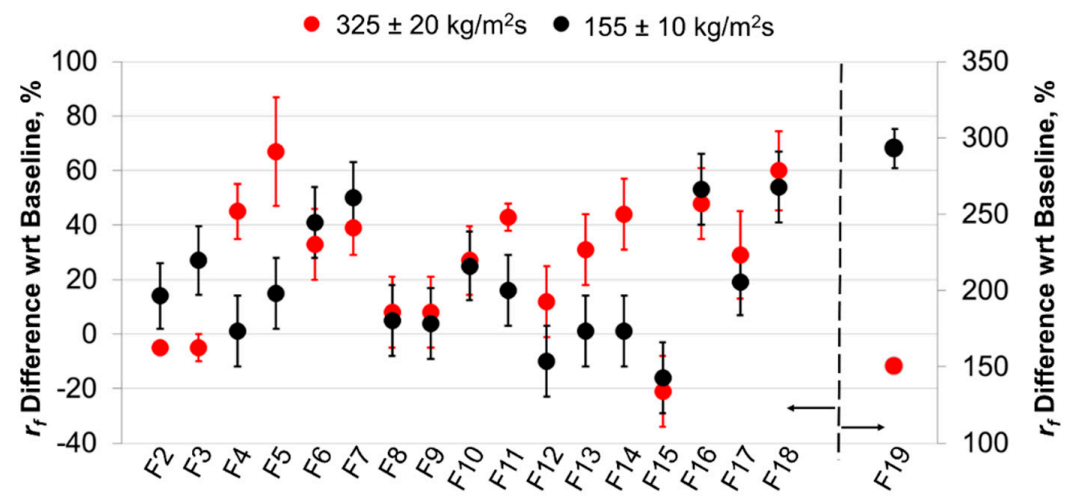

(a)

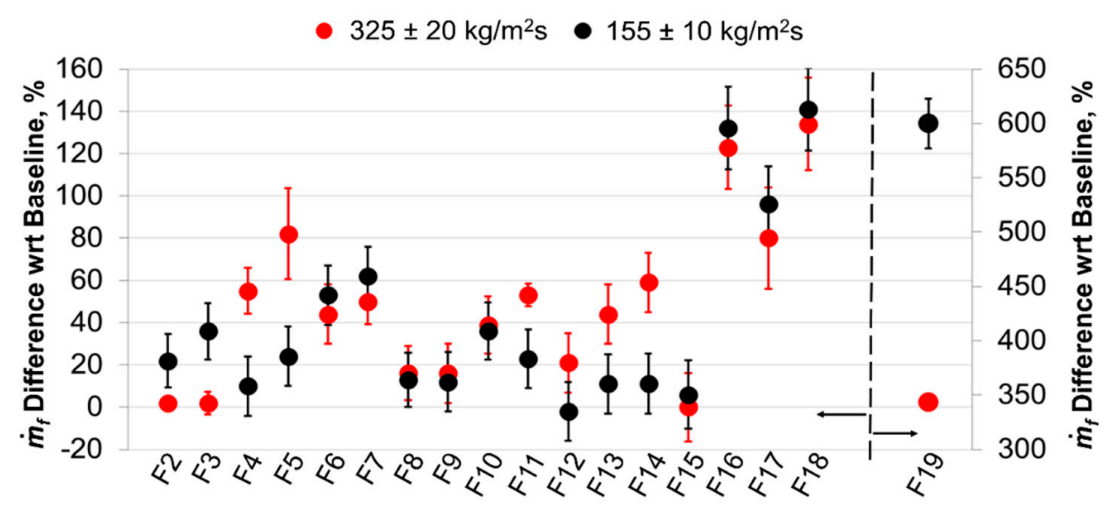

(b)

Figure 7. Relative ballistic grading of the tested fuel formulations (GOX, $p_{c}=1.0 \mathrm{MPa}$, time-resolved instantaneous data): (a) $r_{f}$ and (b) $\dot{m}_{f}$ differences with respect to the baseline. 


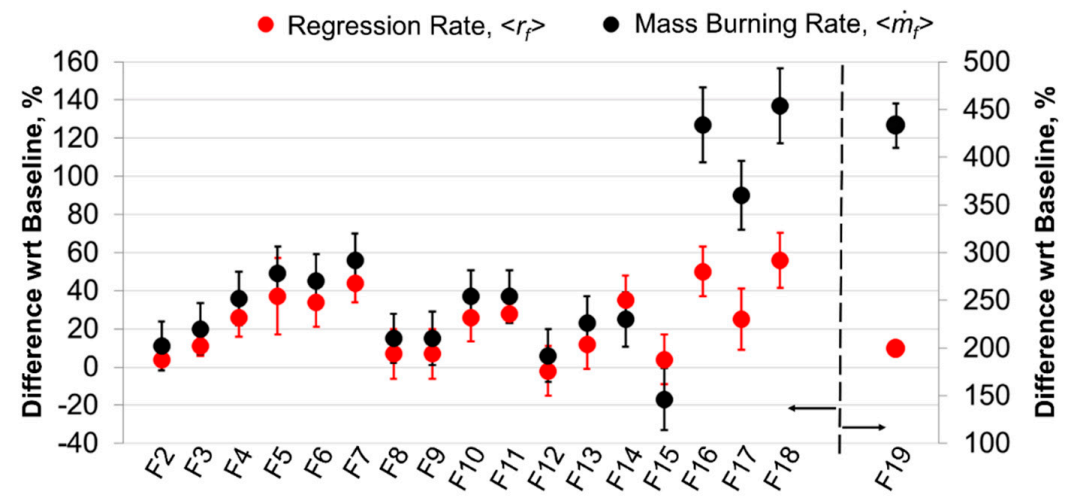

Figure 8. Relative ballistic grading of the tested formulations (GOX, $p_{c}=1.0 \mathrm{MPa}$, time-averaged data) for $\left\langle G_{o x}\right\rangle=(250 \pm 15) \mathrm{kg} /\left(\mathrm{m}^{2} \cdot \mathrm{s}\right):\left\langle r_{f}\right\rangle$ and $\left\langle\dot{m}_{f}\right\rangle$ differences with respect to the baseline.

Table 6. Power law approximation of time-resolved $r_{f}\left(G_{0 x}\right)$ (Equation (3)) for the investigated formulations (F1A and F1B were used as baselines for the relative grading with $\dot{m}_{0 x}$ of $5 \mathrm{~g} / \mathrm{s}$ and $6 \mathrm{~g} / \mathrm{s}$ respectively).

\begin{tabular}{cccc}
\hline Solid Fuel & \multicolumn{2}{c}{$\boldsymbol{r}_{\boldsymbol{f}}\left(\boldsymbol{G}_{\boldsymbol{o x}}\right)$ Power Law Approximation (Equation (3)) } \\
\hline ID & $\boldsymbol{a}_{\boldsymbol{r}}$ & $\boldsymbol{n}_{\boldsymbol{r}}$ & $\boldsymbol{R}^{\mathbf{2}}$ \\
\hline F1A & $0.018 \pm 0.001$ & $0.680 \pm 0.003$ & 0.88 \\
F1B & $0.026 \pm 0.000$ & $0.652 \pm 0.002$ & 0.96 \\
F2 & $0.059 \pm 0.001$ & $0.477 \pm 0.001$ & 0.95 \\
F3 & $0.064 \pm 0.001$ & $0.494 \pm 0.001$ & 0.90 \\
F4 & $0.005 \pm 0.001$ & $0.959 \pm 0.022$ & 0.85 \\
F5 & $0.007 \pm 0.001$ & $0.905 \pm 0.012$ & 0.96 \\
F6 & $0.052 \pm 0.003$ & $0.535 \pm 0.010$ & 0.91 \\
F7 & $0.041 \pm 0.003$ & $0.595 \pm 0.014$ & 0.85 \\
F8 & $0.017 \pm 0.000$ & $0.630 \pm 0.002$ & 0.95 \\
F9 & $0.016 \pm 0.000$ & $0.643 \pm 0.002$ & 0.92 \\
F10 & $0.019 \pm 0.000$ & $0.747 \pm 0.002$ & 0.91 \\
F11 & $0.006 \pm 0.000$ & $0.902 \pm 0.003$ & 0.93 \\
F12 & $0.006 \pm 0.000$ & $0.897 \pm 0.002$ & 0.95 \\
F13 & $0.006 \pm 0.000$ & $0.954 \pm 0.002$ & 0.95 \\
F14 & $0.006 \pm 0.000$ & $0.491 \pm 0.001$ & 0.96 \\
F15 & $0.065 \pm 0.000$ & $0.869 \pm 0.002$ & 0.94 \\
F16 & $0.011 \pm 0.000$ & $0.815 \pm 0.003$ & 0.94 \\
F17 & $0.012 \pm 0.002$ & $0.769 \pm 0.002$ & 0.88 \\
F18 & $0.021 \pm 0.002$ & $0.053 \pm 0.000$ & 0.95 \\
F19 & $1.969 \pm 0.002$ & & 0.88 \\
\hline
\end{tabular}

In spite of the (minor) differences in the operating conditions, solid fuel formulations loaded with $\mu \mathrm{Al}$ (F2 and F3) featured similar ballistic responses (see Figures 7 and 8). The $r_{f}\left(G_{o x}\right)$ of F3 is shown in Figure 9a. Fuels loaded with $\mu \mathrm{Al}$ exhibited no significant performance enhancement over the baseline for $G_{o x}>200 \mathrm{~kg} /\left(\mathrm{m}^{2} \cdot \mathrm{s}\right)$. This reflected the relatively low TG reactivity of these additives (see Table 5), yielding limited heat transfer enhancement for high oxidizer mass fluxes (long burning/reaction time). Faint $r_{f}$ and $\dot{m}_{f}$ increases were achieved for $G_{o x}=155 \mathrm{~kg} /\left(\mathrm{m}^{2} \cdot \mathrm{s}\right)$, thanks to the radiation heat transfer that mitigated the effects of convective heat transfer decrease (as testified by the $n_{r} \sim 0.5$ in Table 6).

The F4 showed marked $r_{f}$ and $\dot{m}_{f}$ increases over the baseline for relatively high $G_{o x}$ (see Figure 7). This performance was quickly lost as the convection decreased, as testified by the $r_{f}\left(G_{o x}\right)$ power law approximation reported in Table 6, and by the low $G_{0 x}$ data of Figure 7. The time-averaged data of Figure 8 captured this effect, as testified by $\left\langle r_{f}\right\rangle=26 \% \pm 10 \%$, in turn yielding $\left\langle\dot{m}_{f}\right\rangle=36 \% \pm 14 \%$. In the high- $G_{0 x}$ region, the augmented flame temperature obtained thanks to ALEX-100 combustion increased the convective heat transfer, and the emitting particles enhanced the radiation contribution. Figure 10 
shows images captured during F4 combustion. In the earlier phases of the combustion, small and bright slivers detached from the regressing surface and from the strand head-end (Figure 10a,b). As the burning proceeded (Figure 10c,d), the formation of a surface crust layer was observed at the head-end (but likely also on the regressing surface). The creation of this surface layer was not observed in $\mu$ Al-loaded fuels (see Figure 3). A more detailed discussion of this phenomenon is given in Section 5.2, where $\mathrm{Al}$ aggregation/agglomeration phenomena are discussed.

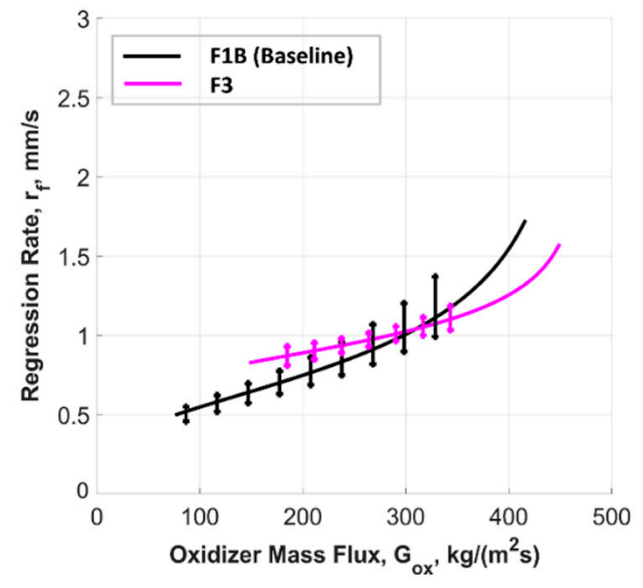

(a)

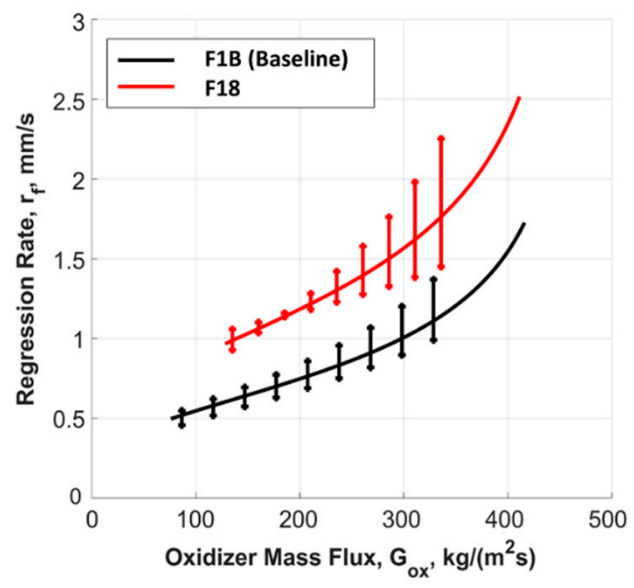

(b)

Figure 9. Time-resolved $r_{f}\left(G_{o x}\right)$ in GOX with $p_{c}=1.0 \mathrm{MPa}$ (a) F3 and (b) F18.

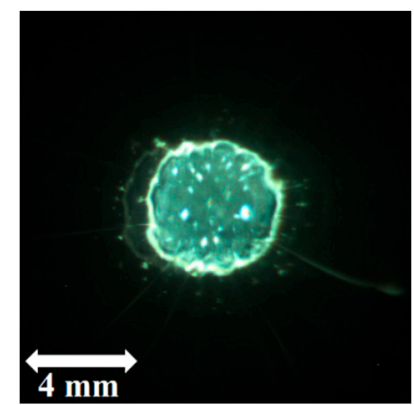

(a) $G_{o x}=265 \pm 16 \mathrm{~kg} /\left(\mathrm{m}^{2} \cdot \mathrm{s}\right)$

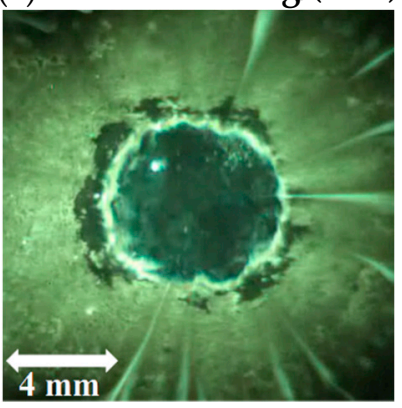

(c) $G_{o x}=165 \pm 10 \mathrm{~kg} /\left(\mathrm{m}^{2} \cdot \mathrm{s}\right)$

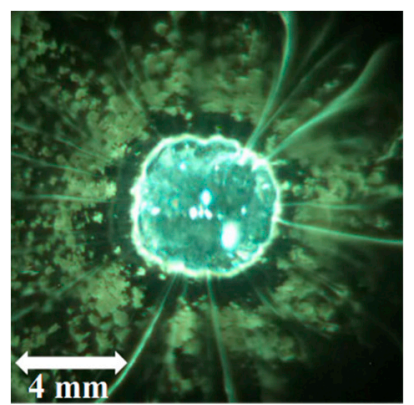

(b) $G_{o x}=230 \pm 14 \mathrm{~kg} /\left(\mathrm{m}^{2} \cdot \mathrm{s}\right)$

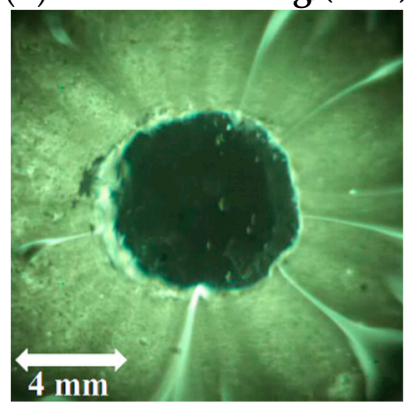

(d) $G_{o x}=125 \pm 8 \mathrm{~kg} /\left(\mathrm{m}^{2} \cdot \mathrm{s}\right)$

Figure 10. Head-end visualization of F4 burning in GOX at $p_{c}=1.0 \mathrm{MPa}$ : (a,b) bright slivers detached from the regressing surface and from the visible strand end, $(\mathbf{c}, \mathbf{d})$ a surface crust layer is formed. Note that no fuel fragments and condensed combustion products are released from the sample toward the end of the combustion.

Interestingly, the nAl-loaded formulation manufactured without additive dispersion techniques (F8) showed no performance enhancement over the corresponding baseline probably due to the metal particle clustering inhibiting Al combustion (see Figures 7 and 8). The F5 showed $r_{f}$ performance and $G_{o x}$ sensitivity similar to F4, as testified by the data reported in Figure 7 (note the relatively 
high error bars for $\left.G_{o x}=325 \mathrm{~kg} /\left(\mathrm{m}^{2} \cdot \mathrm{s}\right)\right)$ and Table 6 . The stearic acid coating exerted no marked influence on the powder characteristics (Table 4) and reactivity (Table 5); this surface treatment was implemented mainly for storage purposes. The solid fuel formulations F6 and F7 exhibited a limited $r_{f}$ dependence on $G_{o x}$ (see Table 6), while providing interesting instantaneous and time-averaged $\dot{m}_{f}$. In particular, these formulations featured a nearly uniform $\dot{m}_{f}$ enhancement over the baseline for the whole investigated $G_{o x}$ range. This suggests that, at high heating rates, the metal reaction with fluoropolymer decomposition products may enhance the metal combustion performance close to/at the regressing surface in both high- and low- $G_{0 x}$ regimes. Such an effect was not observed at slow heating rate (see Table 5). Data reported in Figure 7 showed that, for $G_{o x}=155 \mathrm{~kg} /\left(\mathrm{m}^{2} \cdot \mathrm{s}\right)$, the average $\dot{m}_{f}$ increase over the baseline of F6 and F7 were $53 \% \pm 14 \%$ and $62 \% \pm 14 \%$, respectively, with marked differences with respect to the ALEX-loaded fuel.

The ballistic responses of fuel formulations loaded with VF-ALEX showed similarities with the burning behavior of F10. The AP-ALEX-100B-loaded formulation featured an average $\dot{m}_{f}$ increase over the baseline of $\sim 37 \%$ over the whole investigated $G_{o x}$ range (see Figure 7 ). The $A P$ content in the solid fuel was $\sim 2 \mathrm{wt} . \%$; however, locating it in the composite powder enabled a maximization of the oxidizer impact formulation ballistic response. This was testified by the fact that F9 (same nominal composition of F10, but with AP and nAl that were added separately) showed no significant performance enhancement over the baseline (see Figures 7 and 8). The performance difference between F10 and the VF-ALEX-100-loaded fuel was partially due to the higher SSA and reduced particle size of the latter, promoting the additive reactivity at fast heating rates and compensating for the higher flame temperature of $\mathrm{Al}+\mathrm{AP}$ (see Table 2).

Data for F11 burning with $G_{o x}=325 \mathrm{~kg} /\left(\mathrm{m}^{2} \cdot \mathrm{s}\right)$ showed that the $\dot{m}_{f}$ enhancement of $\mu$ Al15 was improved by the LE mechanical activation (see Figures 7 and 8). Similarly to F4, F11 showed reduced $r_{f}$ and $\dot{m}_{f}$ performance as $G_{o x}$ decreased. The TG analyses suggested a slightly improved reactivity of LE- $\mu \mathrm{Al} 15$ with respect to the starting $\mu \mathrm{Al}$ (see $\alpha(933 \mathrm{~K})$ and $\alpha(1273 \mathrm{~K})$ in Table 5), although the SSA of the powders featured no significant differences. The morphology of LE- $\mu$ Al15 was the likely reason for the augmented reactivity of the powder at the high heating rates encountered in the combustion process. In addition to this, the irregular shape of particles of LE- $\mu$ Al15 may augment the gasifying surface roughness when protruding from the regressing fuel grain. As an effect, the increased surface roughness may have played a minor role in the $r_{f}$ enhancement of F11.

The ballistic effects of the fuels loaded with $\mathrm{Al}+\mathrm{PTFE}$ composites obtained from LE mechanical activation showed no differences for $G_{o x}=155 \mathrm{~kg} /\left(\mathrm{m}^{2} \cdot \mathrm{s}\right)$. On the other hand, for $G_{o x}=325 \mathrm{~kg} /\left(\mathrm{m}^{2} \cdot \mathrm{s}\right)$, the ballistic response of F14 exhibited a $r_{f}$ increase over the baseline of $44 \% \pm 13 \%$. This corresponded to an $\dot{m}_{f}$ enhancement of $59 \% \pm 15 \%$. In Figure 7, the uncertainty interval of F14 data at high $G_{o x}$ partially overlapped those of F12 and F13. In spite of this, it should be noted that the average $r_{f}$ and $\dot{m}_{f}$ increases over the baseline of the fuels loaded with PTFE- $\mu \mathrm{Al}$ composites from LE activation showed higher values as the fluoropolymer content was risen and the particle size of the starting $\mathrm{Al}$ was reduced (see Tables 4 and 5 and Figure 7). Under the investigated conditions, the presence of a particle fraction of sub-micrometric size probably played a key role in the effectiveness of the activation process of $\mu$ Al7.5, compensating for the lubricant effect of the PTFE.

The use of an HE process enabled the production of Al + PTFE composites by more intense activation stresses. These, in turn, permitted higher fluoropolymer mass fractions in the composites than the LE procedure. Under the investigated conditions, the solid fuels loaded with additives produced by HE mechanical activation featured the highest $\dot{m}_{f}$ performance enhancements (see Figures 7 and 8). F15 showed no significant $\dot{m}_{f}$ enhancement over the baseline, since the exploitation of PTFE as the oxidizer required the presence of additional metal ingredients (acting as fluorine scavengers $[10,24,87])$. Formulations in which the Al-PTFE reaction was exploited showed enhanced ballistic performance over non-loaded HTPB in terms of both $r_{f}$ and $\dot{m}_{f}$. For F17, $r_{f}$ enhancements were mainly observed for $G_{o x}<250 \mathrm{~kg} /\left(\mathrm{m}^{2} \cdot \mathrm{s}\right)$, due to a relatively low impact of the Al + PTFE reaction on the metal combustion under intense convection. This was possibly related to the slow heating rate 
behavior of HE- $\mu$ Al15-T45 (see Table 5). This powder showed a relatively low $\alpha$ (1273 K), and a higher $T_{o n, 1}$ with respect to LE- $\mu$ Al7.5-T30 and nano-sized additives featuring strong $r_{f}$ increases at high $G_{o x}$. The F16 and F18 formulations featured the same composition, although the former was loaded with mixed ALEX-50 + PTFE (separated and not mechanically activated powders), while the second was loaded with HE-ALEX-50-T45. The ballistic response of F18 was similar to that of F16, as reported in Figure 7. Both formulations featured strong data dispersion in the early phases of the combustion, with ensemble uncertainty intervals close to those of the baseline formulation. For this reason, in Figure 7, the data for $r_{f}$ and $\dot{m}_{f}$ increases of F18 at $325 \pm 20 \mathrm{~kg} /\left(\mathrm{m}^{2} \cdot \mathrm{s}\right)$ are presented without error bars. As combustion proceeded, data scattering was reduced, and F18 showed percentage $r_{f}$ enhancements over the baseline of $54 \% \pm 13 \%$ at $155 \pm 10 \mathrm{~kg} /\left(\mathrm{m}^{2} \cdot \mathrm{s}\right)$. Under these operating conditions, the uncertainties in the performance enhancement were as for the other formulations, showing interesting performance with an $\dot{m}_{f}$ increase over the baseline of $141 \% \pm 20 \%$ (see Figure 7). F16 and F18 showed similar ballistic responses. This was partially due to the high PTFE and nAl loads providing good fluoropolymer and metal dispersion (fuel slurry was treated by ultrasound irradiation, thus mitigating metal particle clustering). Thus, the relative grading was performed in conditions favoring F16. In addition to this, three points should be highlighted to understand the advantages offered by F18: (i) the implemented HE activation procedure parameters used in this study aimed at a simple diffusion distance reduction between $\mathrm{Al}$ and PTFE, without pursuing further reactivity increases, (ii) the preparation of this fuel formulation proceeded in a simpler way than that of F16 since the micron-sized HE-ALEX-50-T45 was added to the formulation as a single ingredient that did not require ultrasound irradiation for effective dispersion and reduced the fuel formulation viscosity (see PSD and SSA data in Table 4), and (iii) the use of a micron-sized composite based on $\mathrm{nAl}$ reduced the risks of particle suspension in air due to the use of a nano-sized ingredient. In spite of the high metal load, neither F16 nor F18 showed evidence of regressing surface phenomena inhibiting the nAl combustion. F19 showed a ballistic response that was not dependent on $G_{0 x}$, while, for the other PTFE-loaded formulations, the $r_{f}\left(G_{o x}\right)$ power law approximations yielded $n_{r} \sim 0.8$ (see Table 6). Thanks to this, the $\dot{m}_{f}$ enhancement over the baseline of F19 exceeded $600 \%$ for $G_{o x}=155 \mathrm{~kg} /\left(\mathrm{m}^{2} \cdot \mathrm{s}\right)$. These interesting results show the possibilities offered by fuel-rich composite additives, although the optimization of their performance requires future investigations to evaluate the impact of the high $\mathrm{Al}+$ PTFE mass fraction on the nature of the formulation combustion behavior and, in particular, on its PDL.

\subsubsection{Combustion Surface Visualization}

Combustion surface visualizations were performed on selected fuel formulations (F1, F3, F4, F8, F17, F18, and F19). The F1 was tested to provide details on the non-metallized baseline behavior, while the surface behavior of F3 provided insight into the solid fuel surface phenomena in the presence of the standard $\mu \mathrm{Al}$. A comparative analysis of F4 and F8 enabled a comparison of the burning behavior of nAl-loaded fuels with and without sonication for additive dispersion. The PTFE-containing formulations F17, F18, and F19 were tested to evaluate the surface phenomena characterizing the fuels featuring the highest metal powder load and ballistic performance.

Figure 5 shows a representative frame for the combustion of F1. The burning proceeded uniformly along the visible sample length. High-speed visualization of the HTPB binder burning with 100 $\mathrm{kg} /\left(\mathrm{m}^{2} \cdot \mathrm{s}\right) \leq G_{o x} \leq 400 \mathrm{~kg} /\left(\mathrm{m}^{2} \cdot \mathrm{s}\right)$ revealed the detachment of small fragments from the fuel grain [63]. This phenomenon was not observed under the investigated conditions. The image sequences reported in Figure 11 and in Figure 12 show the combustion of F3 and F4, respectively. The fuel loaded by the micron-sized additive featured a combustion surface similar to that of F1, but with the detachment of small elements of intense brightness (see Figure 11). These were $\mathrm{Al}$ particles or agglomerates released by the burning surface. The composition of these elements included $\mathrm{Al}, \mathrm{Al}_{2} \mathrm{O}_{3}$, and (probably) binder decomposition products. The image sequence of Figure 11e-g shows the protrusion from the regressing surface of an apparently non-ignited spherical aggregate (apparent size of $\sim 200 \mu \mathrm{m}$ ). The latter was 
then inflamed during its flow in the boundary layer, as testified by the growth of its brightness and by the appearance of a diffusion trail.

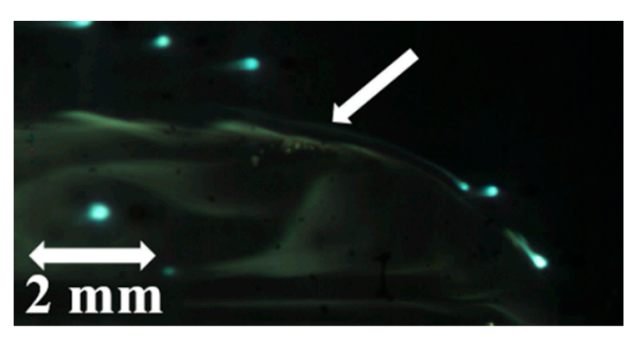

(a) $t_{i g n}+497.8 \mathrm{~ms}$

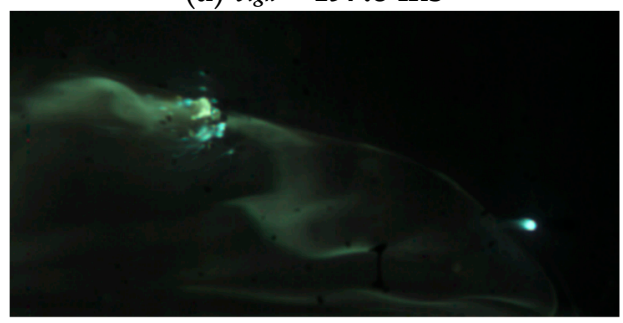

(c) $t_{i g n}+500.3 \mathrm{~ms}$

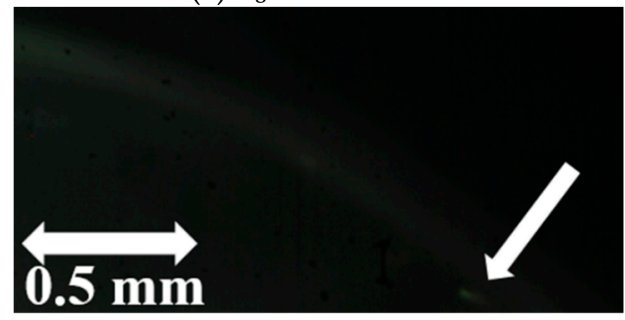

(e) $t_{i g n}+606.9 \mathrm{~ms}$

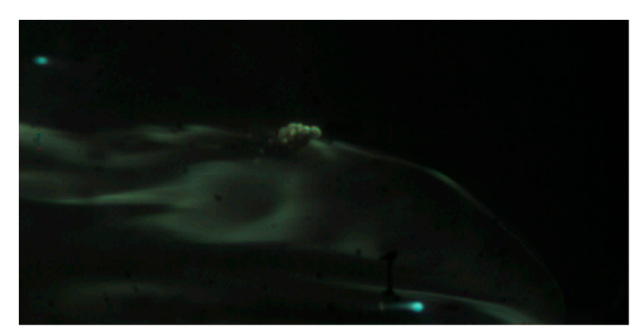

(b) $t_{i g n}+499.4 \mathrm{~ms}$

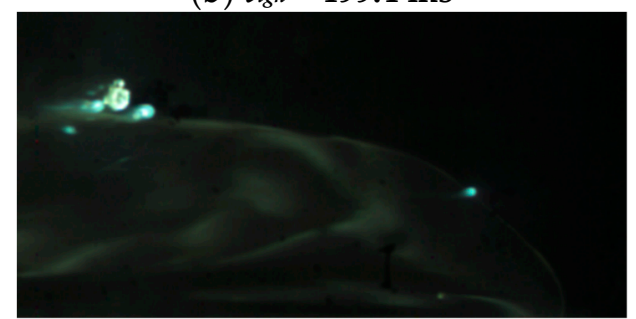

(d) $t_{i g n}+500.8 \mathrm{~ms}$

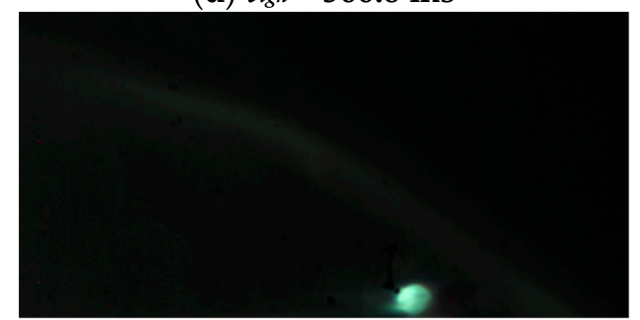

(f) $t_{i g n}+608.9 \mathrm{~ms}$

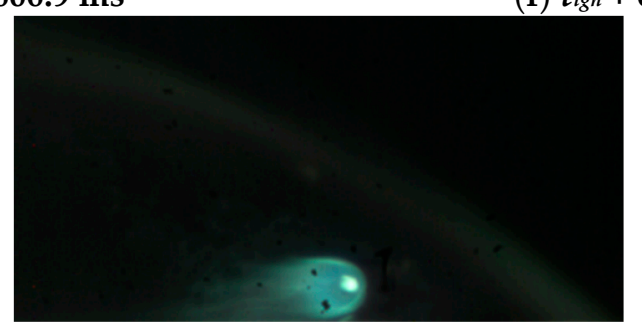

(g) $t_{i g n}+609.7 \mathrm{~ms}$

Figure 11. Combustion visualization of F2 fuel $\left(G_{o x}, p_{c}=0.4 \mathrm{MPa}\right.$, oxidizer flow from right to left): $(\mathbf{a}-\mathbf{d})$ overall view with details of metal particles blown from the surface; $(\mathbf{e}-\mathbf{g})$ details of agglomerate combustion after release from the solid fuel grain. 


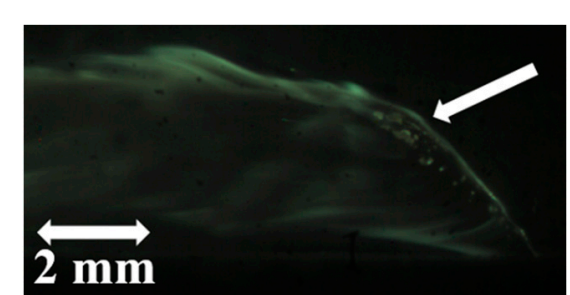

(a) $t_{i g n}+219.4 \mathrm{~ms}$

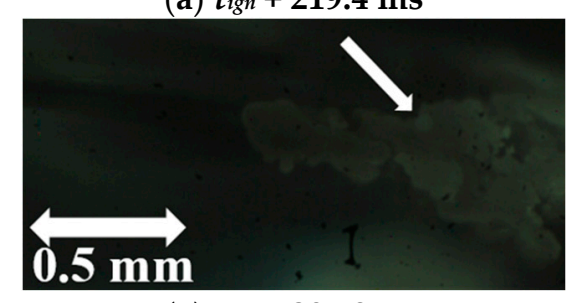

(e) $t_{i g n}+397.0 \mathrm{~ms}$

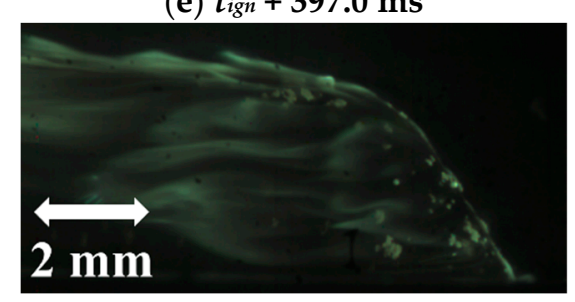

(i) $t_{i g n}+135.9 \mathrm{~ms}$

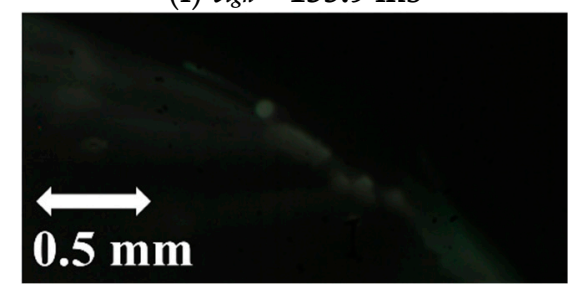

(m) $t_{i g n}+343.6 \mathrm{~ms}$

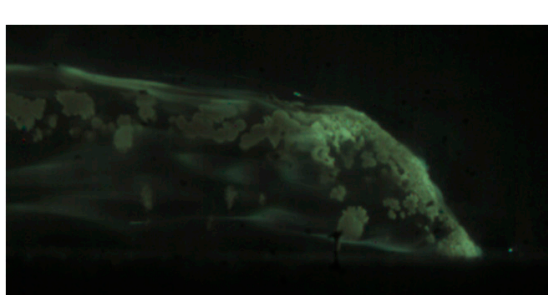

(b) $t_{i g n}+316.5 \mathrm{~ms}$

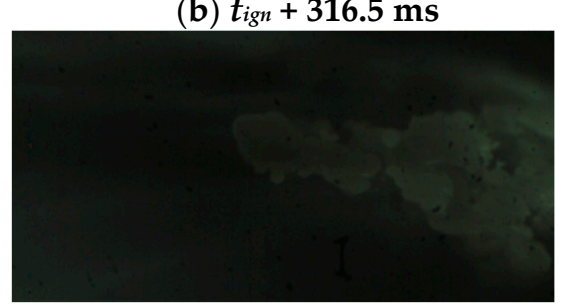

(f) $t_{i g n}+397.6 \mathrm{~ms}$

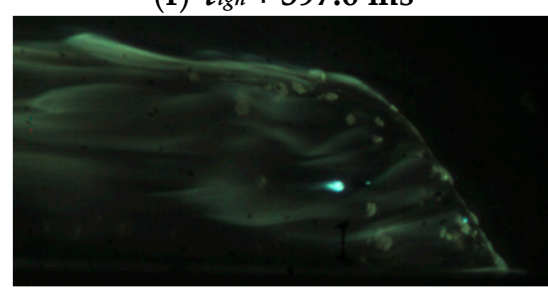

(j) $t_{\text {ign }}+136.2 \mathrm{~ms}$

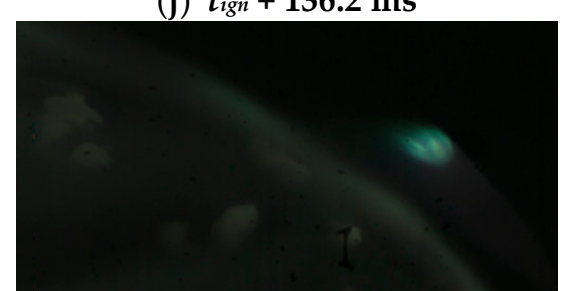

(n) $t_{i g n}+344.0 \mathrm{~ms}$

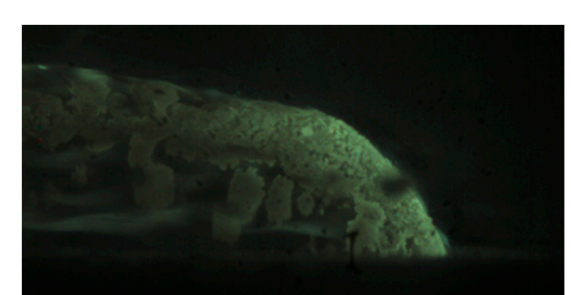

(c) $t_{i g n}+779.7 \mathrm{~ms}$

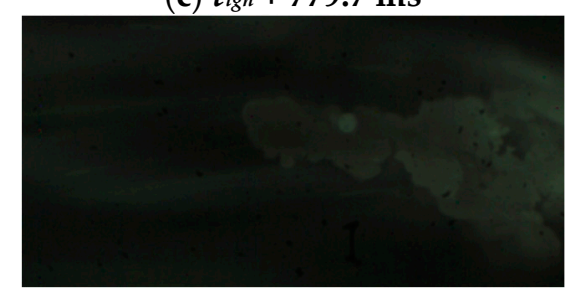

(g) $t_{i g n}+397.9 \mathrm{~ms}$

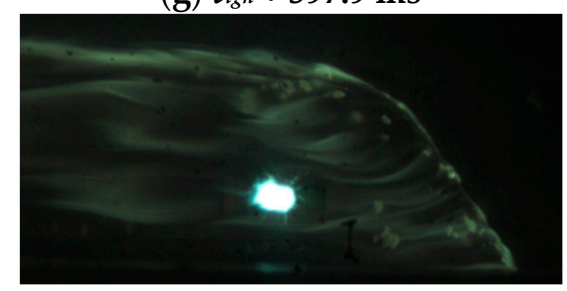

(k) $t_{i g n}+136.5 \mathrm{~ms}$

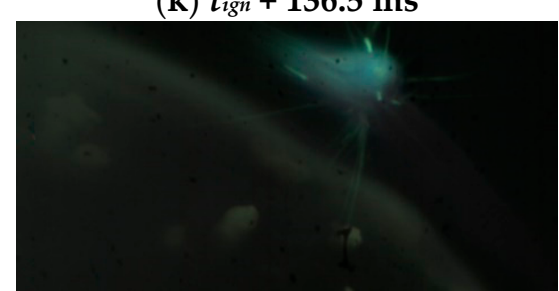

(o) $t_{i g n}+347.4 \mathrm{~ms}$

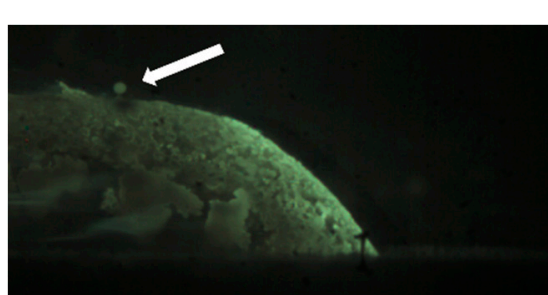

(d) $t_{i g n}+1941.7 \mathrm{~ms}$

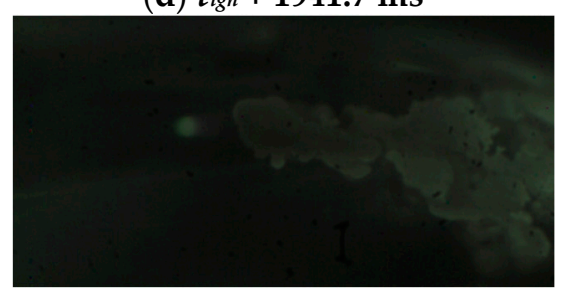

(h) $t_{i g n}+398.3 \mathrm{~ms}$

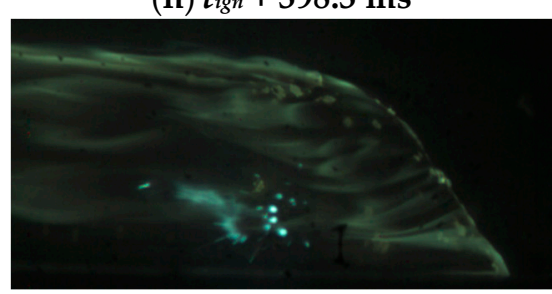

(1) $t_{i g n}+136.6 \mathrm{~ms}$

Figure 12. Combustion visualization of $\mathrm{F} 4$ and $\mathrm{F} 8$ fuel formulations $\left(G_{o x}, p_{c}=0.4 \mathrm{MPa}\right.$, oxidizer flow from right to left): (a-d) formation of layered structure due to nAl aggregation in F4, (e-h) details of aggregate formation and detachment in F4, (i-1) metal agglomerates (possibly including pyrolyzing binder) detaching from the combustion surface of F8 and its fragmentation, (m-o) fragmentation of an aggregate structure from F8 burning surface. 
Under the investigated conditions, the velocity of the gaseous mass blown from the regressing surface was relatively slow (approximately one order of magnitude lower than in solid propellant formulations), while the surface layer exerted relatively intense retention forces due to the viscosity of the pyrolyzing fuel. As a consequence, $\mu$ Al-7.5 showed a faint activity at the gasifying surface (where temperature should be in the range of the $\mathrm{Al}$ melting point). On the one hand, this low activity limited the particle aggregation at the regressing surface and, in particular, the creation of a crust layer hampering the combustion. On the other hand, the metal powder characteristics hindered the additive enthalpy release close to the regressing surface once the particle was captured by the oxidizer stream. The condensed products leaving the regressing surface featured an apparent particle size of 100-200 $\mu \mathrm{m}$ (this observed size is not statistically relevant, and it should be taken as a rough estimation). Such a particle size range suggested relatively long burning times with energy release occurring far from the fuel grain (see Figure 11a and, for a convenient comparison with the burning tests, Figure 3). F4 showed a different burning behavior with respect to both F1 and F3. In the early phases of the combustion, the gasifying surface of HTPB + ALEX-100 showed the insurgence of a marked nAl aggregation (see Figure 12a-d, with the white arrow in Figure 12a highlighting the point the surface layer formation started at). This phenomenon probably began in the sub-surface layer of the pyrolyzing fuel. The insurgence of this surface layer was the likely cause of the fast decrease of the $r_{f}$ and $\dot{m}_{f}$ performance observed in the F4 combustion tests (see Figure 7, Figure 8, and Figure 12). Under the investigated conditions, the time-resolved $r_{f}$ of F8 showed no significant performance enhancement with respect to the baseline. Observing the image sequence reported in Figure 12i-l, a reduction in the aggregation phenomena characterizing F4 was noted for this fuel. The similarities between the high-speed surface visualization of $\mathrm{F} 3$ and $\mathrm{F} 8$ captured the effect of the reduction of $\mathrm{nAl}$ reactivity due to clustering, with a limited $r_{f}$ effect caused by the relatively large size of the $\mathrm{Al}$ agglomerates detaching from the surface (see Figure 12j).

Under the tested $G_{0 x}$ conditions, these aggregates were not detached from the fuel grain and gradually covered the entire gasifying surface of the port. As a result, the vaporization surface was shielded from the flame by a layer of unreacted (or partially oxidized) metal. This condition is shown in Figure 12d. Under these circumstances, the heat feedback to the solid fuel grain was reduced by the missed/incomplete metal oxidation.

The highly loaded fuel compositions with $\mathrm{Al}$ and PTFE featured a regressing surface with a glowing appearance (see Figure 13). This was a possible effect of the reaction between $\mathrm{Al}$ and the fluoropolymer. Independently from the micro- or nano-metric size of the $\mathrm{Al}$ particles embedded in the formulation, F17, F18, and F19 featured a surface layer that was apparently weaker than that formed in F4. This surface layer was also easily exfoliated by the oxidizer flow in the (relatively low) $G_{0 x}$ conditions tested in the high-speed visualizations. The weakness of the surface layer limited (or avoided) the inhibition of heat feedback to the solid fuel grain encountered with F4. As a result, metal combustion occurred in more favorable conditions and, therefore, $r_{f}$ enhancement was achieved. 


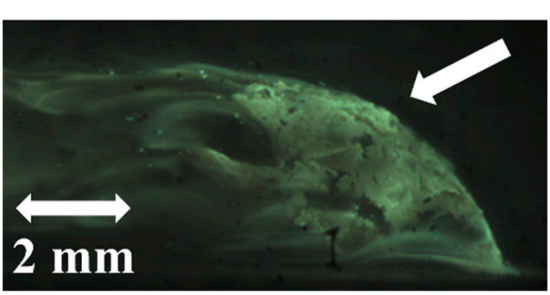

(a) $t_{i g n}+758.7 \mathrm{~ms}$

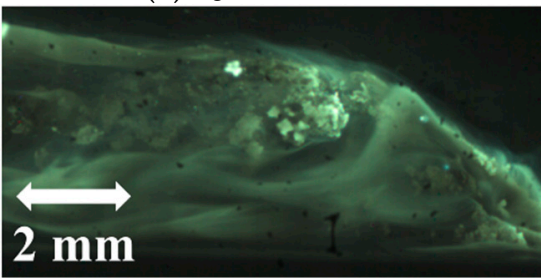

(e) $t_{i g n}+1092.2 \mathrm{~ms}$

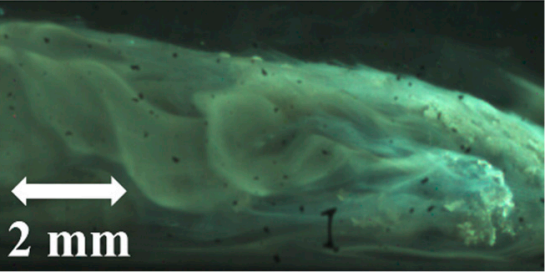

(i) $t_{i g n}+506.6 \mathrm{~ms}$

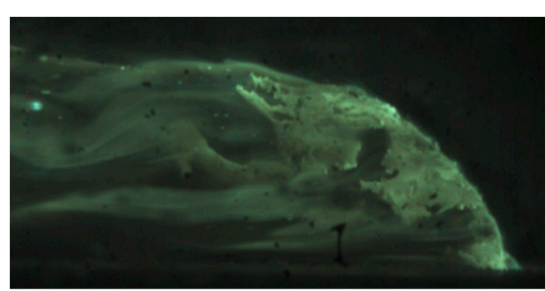

(b) $t_{i g n}+767.3 \mathrm{~ms}$

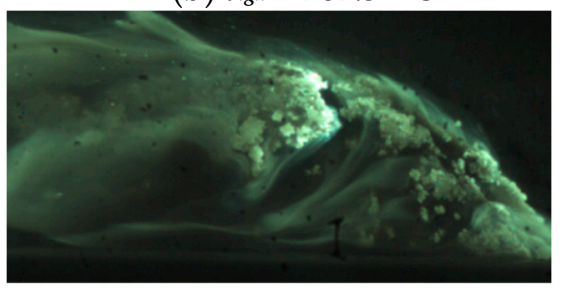

(f) $t_{i g n}+1109.3 \mathrm{~ms}$

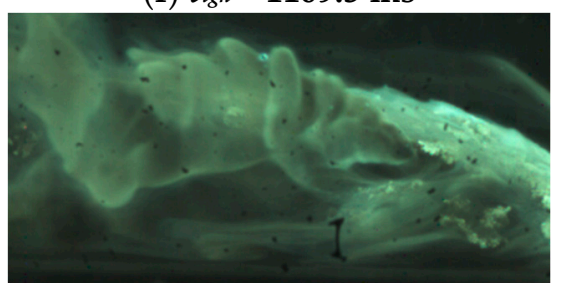

(j) $t_{i g n}+588.1 \mathrm{~ms}$

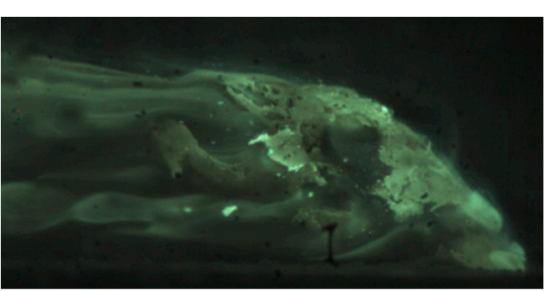

(c) $t_{i g n}+769.5 \mathrm{~ms}$

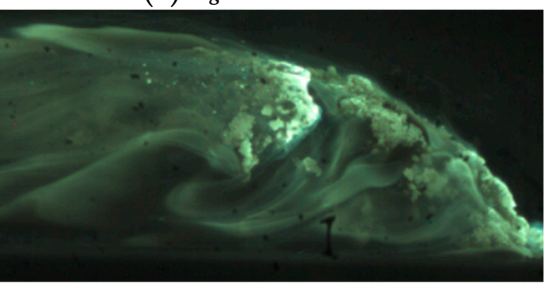

(g) $t_{i g n}+1119.7 \mathrm{~ms}$

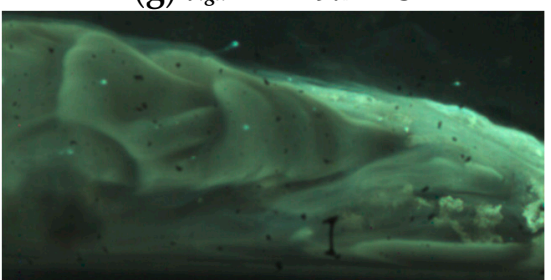

(k) $t_{i g n}+602.8 \mathrm{~ms}$

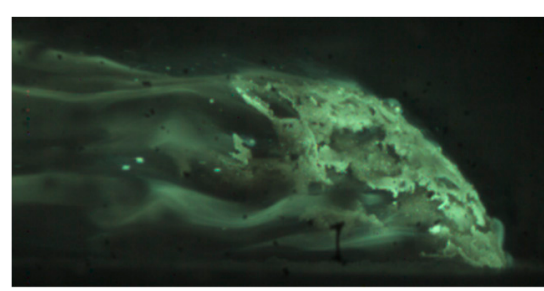

(d) $t_{i g n}+776.3 \mathrm{~ms}$

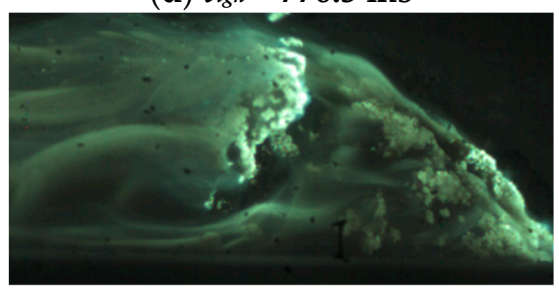

(h) $t_{i g n}+1125.8 \mathrm{~ms}$

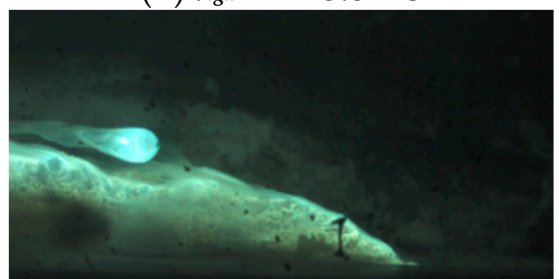

(1) $t_{i g n}+859.8 \mathrm{~ms}$

Figure 13. Combustion visualization of F17, F18, and F19 fuel formulations ( $G_{o x}, p_{c}=0.4 \mathrm{MPa}$, oxidizer flow from right to left): (a-d) F17 and (e-h) F18 burning surfaces feature a surface layer undergoing exfoliation and fragmentation, (i-1) F19 combustion shows the detachment of fine fragments from the regressing surface (see $t=t_{i g n}+602.8 \mathrm{~ms}$ ) and, toward the end of the combustion $\left(t=t_{\text {ign }}+859.8 \mathrm{~ms}\right)$, agglomerates of relatively large apparent size $(\sim 1 \mathrm{~mm})$ protruding and being released from the fuel slab after ignition. 


\subsubsection{Concluding Remarks}

The screening of different fuel formulations was performed starting from the pre-burning characterization of a variety of Al-based energetic fillers. Composite additives were investigated together with air-passivated $\mu \mathrm{Al}$ and $\mathrm{nAl}$. Effects of ingredients as $\mathrm{AP}$ and fluoropolymers on the metal ignition and combustion in the oxidizer-lean conditions encountered at/close to the regressing surface of burning fuel formulations were investigated.

Under the investigated conditions, F4 showed an $r_{f}$ enhancement over the non-metallized baseline of $59 \% \pm 10 \%$ at $350 \mathrm{~kg} /\left(\mathrm{m}^{2} \cdot \mathrm{s}\right)$ and a marked $r_{f}\left(G_{o x}\right)$ sensitivity. The ballistic performance of the nAl-load formulation worsened as the oxidizer mass flux decreased. The $r_{f}$ increase over the baseline reduced to $45 \% \pm 10 \%$ at $325 \mathrm{~kg} /\left(\mathrm{m}^{2} \cdot \mathrm{s}\right)$ and were absent at $155 \mathrm{~kg} /\left(\mathrm{m}^{2} \cdot \mathrm{s}\right)$. The resulting $\left\langle\dot{m}_{f}\right\rangle$ at $\left\langle G_{o x}\right\rangle=250 \pm 15$ $\mathrm{kg} /\left(\mathrm{m}^{2} \cdot \mathrm{s}\right)$ was $36 \% \pm 14 \%$, and the power law approximation of $r_{f}\left(G_{o x}\right)$ yielded $n_{r}=0.959 \pm 0.022$. The latter value highlighted other effects on the combustion evolution than the convective heat transfer decrease. High-speed visualizations of the burning surface suggested that F4 burning performance loss was mainly caused by metal aggregation occurring at the regressing surface/subsurface. This phenomenon yielded the formation of a shield of unreacted/partially oxidized Al that limited the heat feedback toward the surface. Combustion tests results and surface visualizations supported the idea that high $G_{o x}$ promoted $\mathrm{Al}$ particle/aggregate removal from the surface (and their combustion), as shown by Figures 10 and 12. On the other hand, under $145 \mathrm{~kg} /\left(\mathrm{m}^{2} \cdot \mathrm{s}\right) \leq G_{o x} \leq 160 \mathrm{~kg} /\left(\mathrm{m}^{2} \cdot \mathrm{s}\right)$, the aggregates resided on the fuel surface, creating a crust of accumulated material. This was a likely effect of subsurface aggregation creating a relatively strong web with good cohesion (see Figures 10 and 12). Such behavior was not observed for fuels loaded with $\mu \mathrm{Al}$ (F2-F3) and for F8 (that was prepared without nAl dispersion procedures). These fuels exhibited no significant $r_{f}$ and $\dot{m}_{f}$ enhancements over the baseline at high $G_{0 x}$, while at $155 \mathrm{~kg} /\left(\mathrm{m}^{2} \cdot \mathrm{s}\right), \mu$ Al-loaded fuels showed increased performance over both F4 and F8. For F2-F3, F4, and F8, relatively large aggregates were observed to detach from the surface. The use of AP- and fluoropolymer-containing composites based on Al contrasted the $r_{f}$ detriment observed for ALEX-100, thanks to the metal reaction with the oxidizer/coating decomposition products. In spite of an increased additive (and metal) mass fraction with respect to the other investigated fuels, combustion surface visualizations of F18 showed the build-up of a surface metal layer of reduced cohesion. This was the likely effect of the partial reaction between the metal and the PTFE. The resulting surface layer was easily exfoliated by the oxidizer flow, and faster $r_{f}$ was, therefore, achieved by a combination of convective and radiation effects (see Figures 7 and 8).

\section{Conclusions and Future Developments}

This work focused on the lab-scale investigation of the combustion behaviors of solid fuel formulations based on hydroxyl-terminated polybutadiene loaded with Al-based energetic additives. Tested metal-based fillers spanned from micron- to nano-sized powders and included oxidizer-containing fuel-rich composites. The latter were obtained by chemical and mechanical processes applied to the starting Al powders. The aim of these processes was the reduction of the diffusion distance between the metal and the oxidizing species source, and/or the modification of the particle characteristics (i.e., morphology, size). The chemical and mechanical processes pursued easier $\mathrm{Al}$ ignition and combustion in the oxidizer-lean conditions characterizing the region between the diffusion flame and the regressing surface of the burning grains. The combustion behaviors of the tested formulations were analyzed considering the solid fuel regression rate and the mass burning rate as the main parameters of interest. A non-metallized formulation was taken as baseline for the relative grading of the tested fuels. Instantaneous and time-average regression rate $\left(r_{f}\right)$ and mass burning rate $\left(\dot{m}_{f}\right)$ data were determined using an optical time-resolved technique. The ballistic responses of the fuels were analyzed together with high-speed visualizations of the regressing surface.

The ballistic responses of fuel formulations loaded with uncoated air-passivated nano-sized Al (nominal size $100 \mathrm{~nm}$, ALEX-100) showed a strong dependence on the fuel manufacturing procedure. The dispersion of nano-sized $\mathrm{Al}$ down to the nanoscale requires special manufacturing procedures to 
mitigate the clustering of particles. In the study, a fuel formulation prepared by ultrasound irradiation was contrasted with a similar composition prepared without any effort toward a clustering reduction. For oxygen mass fluxes $>250 \mathrm{~kg} /\left(\mathrm{m}^{2} \cdot \mathrm{s}\right)$, the fuels loaded with ALEX-100 and prepared by nanopowder dispersion procedures showed increased $r_{f}$ and $\dot{m}_{f}$ with respect to formulations where the same additive was included without special treatments. The polymeric fuel loaded with ALEX-100 and prepared by additive dispersion techniques exhibited instantaneous mass burning rate enhancement over the baseline of $55 \% \pm 11 \%$ for an oxidizer mass flux of $325 \pm 20 \mathrm{~kg} /\left(\mathrm{m}^{2} \cdot \mathrm{s}\right)$. This ballistic performance was lost as the oxidizer mass flux decreased, and, at $155 \pm 10 \mathrm{~kg} /\left(\mathrm{m}^{2} \cdot \mathrm{s}\right)$, no significant $\dot{m}_{f}$ increase over the baseline was identified. Under the same operating conditions, a formulation prepared without special procedures for ALEX-100 dispersion yielded a $\dot{m}_{f}$ increase over the baseline of $15 \% \pm 13 \%$ at $325 \pm 20 \mathrm{~kg} /\left(\mathrm{m}^{2} \cdot \mathrm{s}\right)$, and this performance remained nearly unchanged over the whole investigated oxidizer mass flux range.

Combustion surface visualizations performed on ALEX-100-loaded solid fuel slabs burning at oxygen mass fluxes in the range of $145 \mathrm{to} 160 \mathrm{~kg} /\left(\mathrm{m}^{2} \cdot \mathrm{s}\right)$ suggested that the observed ballistic responses were due to different metal aggregation/agglomeration phenomena (in turn induced by the different manufacturing procedures). In fuel formulations prepared by special manufacturing procedures for ALEX-100 dispersion, for oxygen mass flux $<160 \mathrm{~kg} /\left(\mathrm{m}^{2} \cdot \mathrm{s}\right)$, intense aggregation of the metal particles was noted at the burning surface. This phenomenon caused the formation of a crust of sintered and (possibly) partially oxidized metal, inhibiting the combustion process and canceling the performance enhancement over the baseline of the ALEX-100-loaded fuel. Such phenomena were probably limited at relatively high oxygen mass fluxes, thanks to the more intense convection that yielded more effective combustion conditions for ALEX-100. No marked aggregation/agglomeration surface phenomena were observed during the combustion of the ALEX-100-loaded fuel prepared without procedures for additive dispersion. In this latter formulation, clusters of metal particles were ejected from the regressing surface and burned relatively far from it, with a combustion mechanism similar to that observed in fuels loaded with micron-sized Al. This was a consequence of the combustion of relatively large clusters of particles featuring a reduced specific surface area compared to the smaller clusters or single nanoparticles (and, therefore, a lower reactivity). With heat release occurring far from the regressing surface, and a likely incomplete combustion of the clusters, the fuel loaded with ALEX-100 and prepared without additive dispersion procedures yielded a lower performance enhancement at high oxygen fluxes, and a limited $\dot{m}_{f}$ with reduced oxygen mass fluxes.

Composite Al-rich additives limited the negative effects of ALEX-100 aggregation/agglomeration on combustion, while providing increased regression rate and mass burning rate performance over the baseline. The fuel loaded with air-passivated nano-sized Al coated with a copolymer of vinylidene fluoride and hexafluoropropylene showed a mass burning rate enhancement over the baseline of $45 \%$ $\pm 14 \%$ at $155 \mathrm{~kg} /\left(\mathrm{m}^{2} \cdot \mathrm{s}\right)$, with a limited sensitivity of this result with regard to the oxidizer mass flux changes. A similar ballistic response was achieved by a composite featuring nano-sized $\mathrm{Al}$ as fuel, and ammonium perchlorate (AP) as oxidizer. In this case, in spite of the presence of large clusters of nano-sized Al and AP, the $\dot{m}_{f}$ enhancement over the baseline was $39 \% \pm 14 \%$ at $325 \mathrm{~kg} /\left(\mathrm{m}^{2} \cdot \mathrm{s}\right)$ and $36 \% \pm 13 \%$ at $155 \mathrm{~kg} /\left(\mathrm{m}^{2} \cdot \mathrm{s}\right)$. In both the latter formulations, the oxidizer content in the final fuel was $<2 \mathrm{wt} . \%$; thus, a crucial role was played by the limited diffusion distance between the metal and the oxidizing species source. The ballistic responses of the fuels prepared with nAl-based composites produced by chemical methods suggested an interaction between $\mathrm{Al}$ and the oxidizing species in the additive during the combustion. This interaction promoted the metal ignition and combustion, and it lessened the effects of the nano-sized aluminum aggregation under the oxidizer-lean conditions encountered at/close to the regressing surface. This observation was supported by combustion surface visualizations of solid fuels containing mechanically activated composites with nano-sized $\mathrm{Al}$ and polytetrafluoroethylene (PTFE) as oxidizer. This fuel formulation featured an additive load of 54.4 wt. $\%$, with a composition of the energetic filler that was $55 \mathrm{wt} . \%$ air-passivated $\mathrm{nAl}$ (nominal size 50 $\mathrm{nm}$ ) and $45 \mathrm{wt} . \%$ PTFE. In spite of a relatively high nano-sized $\mathrm{Al}$ mass fraction ( $30 \%$ of the whole 
formulation), the fuel loaded with this additive did not show evidence of the formation of a surface layer of aggregated metal hindering the combustion process. The nAl reaction with PTFE favored the metal ignition and combustion at/close to the regressing surface, as in the case of the composites containing fluoropolymer/AP produced by chemical methods. The fuel formulation loaded with the mechanically activated nano-sized $\mathrm{Al}$ and PTFE exhibited augmented performance with respect to the baseline, with a mass burning rate increase of $141 \% \pm 20 \%$ at $155 \mathrm{~kg} /\left(\mathrm{m}^{2} \cdot \mathrm{s}\right)$. Yet, when considering the data scattering between different combustion tests, the performance of the composite additive produced by mechanical activation did not differ significantly from that of fuels containing a simple mix of nano-sized $\mathrm{Al}$ and polytetrafluoroethylene. This result was mainly due to two reasons. Firstly, in this work the mechanical activation procedure for the realization of the nano-sized Al-PTFE composite was not optimized. Secondly, the relatively high PTFE content in the formulation ( $24.5 \mathrm{wt} . \%)$ favored its dispersion in the binder matrix and also reduced the distance between fluoropolymer and metal particles in the case of non-activated, simply mixed ingredients.

The achieved results provide a better understanding of the effects of the use of $\mathrm{nAl}$ in solid fuel formulations, showing the possible detrimental effects due to the metal aggregation observed at relatively low oxidizer mass fluxes. On the other hand, the ballistic responses of fuel formulations loaded with nAl-based composite additives testify that the behavior of the nano-sized metal powders can be tailored to mitigate possible shortcomings due to the oxidizer-lean conditions locally encountered in the reacting boundary layer. Moreover, the use of composite powders promises simplified manufacturing procedures for the production of nAl-containing fuels, since chemical and mechanical activation processes may be designed to provide additives with tailored reactivity and suitable particle size distribution. All these aspects show the attractive perspectives offered by fuel-rich composite additives.

Future activities for augmented $r_{f}$ and $\dot{m}_{f}$ of solid fuels on nAl-based composite additives should focus on (i) combustion efficiency of the fuel formulations loaded with composite additives, (ii) suitability of the proposed approach to liquefying fuel formulations, (iii) impacts of green oxidizers on the preparation of the composites, and (iv) determination of the PDL of the fuel formulations, to evaluate the effects of composite additives on stop/restart and throttling capabilities of solid fuel grains loaded with these additives.

Funding: This research received no external funding.

Acknowledgments: The author thanks Stefano Dossi (ReActive-Powder Technology srl, Milan, Italy) for the work done on the development of procedures for the mechanical activation processes and helpful discussions. The efforts of Marco Castagna and Marco DiLorenzo, who helped with the experimental data collection during their MSc activities at the SPLab of Politecnico di Milano, are highly appreciated. Special thanks go to Gianluigi Marra (Istituto ENI Donegani, Novara, Italy) for the work done on the SEM, TEM, and SSA data collection.

Conflicts of Interest: the author declares no conflicts of interest.

\section{Nomenclature}

Roman and Greek Symbols

$\langle$.

space-averaged value

$\alpha(T)$

$\Delta m_{0}$

$\Delta m(T)$

$\mu \mathrm{Al}$

$\rho_{A l}$

$\rho_{f}$

time-averaged value

$\mathrm{Al} \rightarrow \mathrm{Al}_{2} \mathrm{O}_{3}$ conversion factor, \%

mass change before the first intense oxidation onset temperature, $\%$

$a_{D}$ mass change at the temperature $T, \%$ micron-sized $\mathrm{Al}$ powder

Al density, $\mathrm{kg} / \mathrm{m}^{3}$

fuel density, $\mathrm{kg} / \mathrm{m}^{3}$

$a_{r}$

pre-exponential coefficient in diameter change power law fitting, $\mathrm{mm} / \mathrm{s}^{n D}$

$a_{S}$ pre-exponential coefficient in regression rate power law approximation, $\mathrm{mm} / \mathrm{s} /\left(\mathrm{kg} /\left(\mathrm{m}^{2} \cdot \mathrm{s}\right)\right)^{n r}$ particle size derived from the specific surface area, $\mathrm{nm}$

$C_{A l} \quad$ active $\mathrm{Al}$ content, wt.\% 
$D_{(0.1)} \quad$ particle diameter below which $10 \%$ of the particles lay, $\mu \mathrm{m}$

$D_{(0.5)} \quad$ particle diameter below which $50 \%$ of the particles lay, $\mu \mathrm{m}$

$D_{(0.9)} \quad$ particle diameter below which $90 \%$ of the particles lay, $\mu \mathrm{m}$

$D_{32} \quad$ surface-based mean particle diameter, $\mu \mathrm{m}$

$D_{43} \quad$ volume-based mean particle diameter, $\mu \mathrm{m}$

$D_{i} \quad i$-th sampled port diameter, $\mathrm{mm}$

$G \quad$ total mass flux $\left(G=G_{o x}+G_{f}\right), \mathrm{kg} /\left(\mathrm{m}^{2} \cdot \mathrm{s}\right)$

$G_{f} \quad$ fuel mass flux, $\mathrm{kg} /\left(\mathrm{m}^{2} \cdot \mathrm{s}\right)$

$\mathrm{G}_{0 x} \quad$ oxidizer mass flux, $\mathrm{kg} /\left(\mathrm{m}^{2} \cdot \mathrm{s}\right)$

$L_{f} \quad$ fuel grain length, $\mathrm{m}$

$\dot{m}_{f} \quad$ fuel mass burning rate, $\mathrm{kg} / \mathrm{s}$

$\dot{m}_{o x} \quad$ oxidizer mass flow rate, $\mathrm{kg} / \mathrm{s}$ (except where otherwise stated)

$n A l \quad$ nano-sized Al powder

$n_{D} \quad$ exponent in diameter change power law fitting

$n_{r} \quad$ exponent in regression rate power law approximation

$p_{c} \quad$ combustion chamber pressure, $\mathrm{MPa}$

$R^{2} \quad$ data fitting parameter

$r_{f} \quad$ solid fuel regression rate, $\mathrm{mm} / \mathrm{s}(\mathrm{m} / \mathrm{s}$ in Equation (4))

$T$ temperature, $\mathrm{K}$

$t \quad$ time, s

$t_{\text {end }} \quad$ end time, $\mathrm{s}$

$T_{f l} \quad$ calculated flame temperature, $\mathrm{K}$

$t_{i} \quad$ time of the $i$-th diameter sampling, $\mathrm{s}$

$t_{\text {ign }} \quad$ ignition time, $\mathrm{s}$

$T_{\text {on, } i} \quad i$-th intense oxidation onset temperature, $\mathrm{K}$

Acronyms

ALEX aluminum exploded (nAl produced by electrical explosion of wires, typically air-passivated)

AP ammonium perchlorate

CB carbon black

CCP condensed combustion product

DTG differential of the thermogravimetry trace

GOX gaseous oxygen

HE high energy (mechanical activation)

HRE hybrid rocket engine

HTPB hydroxyl-terminated polybutadiene

LE low energy (mechanical activation)

MA mechanical activation

PDL pressure deflagration limit, $\mathrm{MPa}$

PTFE polytetrafluoroethylene

SEM scanning electron microscopy

SSA specific surface area, $\mathrm{m}^{2} / \mathrm{g}$

SOP small oxide particles

TED transmission energy dispersion

TEM transmission electron microscopy

TOT thickness over time

TG thermogravimetry

TMD theoretical maximum density, $\mathrm{kg} / \mathrm{m}^{3}$

VFHFP vinylidene fluoride hexafluoropropylene copolymer

wrt with respect to

\section{References}

1. Marxman, G.A.; Gilbert, M. Turbulent boundary layer combustion in the hybrid rocket. In 9th International Symposium on Combustion; Academic Press, Inc.: New York, NY, USA, 1963; pp. 371-383. 
2. Marxman, G.A. Boundary layer combustion in propulsion. In 11th Symposium (International) on Combustion; The Combustion Institute: Pittsburg, PA, USA, 1964; pp. 269-289.

3. Marxman, G.A.; Wooldridge, C.E. Research on the Combustion Mechanism of Hybrid Rockets. In Advances in Tactical Rocket Propulsion; Penner, S.S., Ed.; AGARD Conference Proceedings No. 1; Technivision Services: London, UK, 1968; pp. 421-477.

4. Chiaverini, M.J. Review of solid fuel regression rate behavior in classical and non-classical hybrid rocket motors. In Fundamentals of Hybrid Rocket Combustion and Propulsion; Chiaverini, M.J., Kuo, K.K., Eds.; AIAA Progress in Astronautics and Aeronautics: Reston, VA, USA, 2007; Volume 218, pp. 37-125.

5. Marquardt, T.; Majdalani, J. Review of Classical Diffusion-Limited Regression Rate Models in Hybrid Rockets. Aerospace 2019, 6, 75. [CrossRef]

6. Pastrone, D. Approaches to low fuel regression rates in hybrid rocket engines. Int. J. Aerosp. Eng. 2012, 2012, 649753. [CrossRef]

7. Karabeyoglu, M.A.; Altman, D.; Cantwell, B.J. Combustion of liquefying hybrid propellants: Part 1, general theory. J. Propul. Power 2002, 18, 610-620. [CrossRef]

8. Karabeyoglu, M.A.; Cantwell, B.J. Combustion of liquefying hybrid propellants: Part 2, stability of liquid films. J. Propul. Power 2002, 18, 621-630. [CrossRef]

9. Kim, S.; Lee, J.; Moon, H.; Sung, H.; Kim, J.; Cho, J. Effect of paraffin-LDPE blended fuel in hybrid rocket motor. In Proceedings of the 46th AIAA. ASME/SAE/ASEE Joint Propulsion Conference and Exhibit, Nashville, TN, USA, 25-28 July 2010. AIAA Paper No. 2010-7031.

10. Boiocchi, M.; Paravan, C.; Dossi, S.; Maggi, F.; Colombo, G.; Galfetti, L. Paraffin-Based Fuels and Energetic Additives for Hybrid Rocket Propulsion. In Proceedings of the 51st AIAA/SAE/ASEE Joint Propulsion Conference, Orlando, FL, USA, 27-29 July 2015. AIAA Paper No. 2015-4042.

11. Paravan, C.; Galfetti, L.; Maggi, F. A Critical Analysis of Paraffin-based Fuel Formulations for Hybrid Rocket Propulsion. In Proceedings of the 53rd AIAA/SAE/ASEE Joint Propulsion Conference, Atlanta, GA, USA, 10-12 July 2017. AIAA Paper No. 2017-4830.

12. Paravan, C.; Bisin, R.; Piscaglia, F.; Galfetti, L. Combustion Processes in Hybrid Propulsion. Int. J. Energ. Mater. Chem. Propuls. 2019, 18, 255-286.

13. Veale, K.; Adali, S.; Pitot, J.; Brooks, M. A Review of the Performance and Structural Considerations of Paraffin Wax Hybrid Rocket Fuels with Additives. Acta Astronaut. 2017, 141, 196-208. [CrossRef]

14. Tan, Y.; Chen, S.; Zhang, W.; Shen, R.; DeLuca, L.T.; Ye, Y. The Effects of Mechanical Modification Additives on the Regression Rate of Paraffin-Based Fuels for Hybrid Rocket. In Proceedings of the 7th European Conference for Aeronautics and Space Sciences, Milan, Italy, 1-4 July 2017.

15. Risha, G.A.; Evans, B.J.; Boyer, E.; Kuo, K.K. Metals, energetic additives and special binders used in solid fuels for hybrid rockets. In Fundamentals of Hybrid Rocket Combustion and Propulsion; Chiaverini, M.J., Kuo, K.K., Eds.; AIAA Progress in Astronautics and Aeronautics: Reston, VA, USA, 2007; Volume 218, pp. 413-456.

16. Paravan, C. Ballistics of Innovative Solid Fuel Formulations for Hybrid Rocket Engines. Ph.D. Thesis, Politecnico di Milano, Aerospace Science and Technology Department, Milan, Italy, 2012.

17. De Luca, L.T.; Galfetti, L.; Maggi, F.; Colombo, G.; Paravan, C.; Reina, A.; Dossi, S.; Fassina, M.; Sossi, A. Characterization and combustion of aluminum nanopowders in energetic systems. In Metal Nanopowders Production, Characterization, and Energetic Applications; Gromov, A.A., Teipel, U., Eds.; Wiley VCH: Weinheim, Germany, 2014; pp. 299-408.

18. Evans, B.; Favorito, N.A.; Boyer, E.; Risha, G.A.; Wehrman, R.B.; Kuo, K.K. Characterization of Nano-sized Energetic Particle Enhancement of Solid Fuel Burning Rates in an X-Ray Transparent Hybrid Rocket Engine. In Proceedings of the 40th AIAA/ASME/SAE/ASEE Joint Propulsion Conference and Exhibit (AIAA), Fort Lauderdale, FL, USA, 11-14 July 2004. AIAA Paper No. 2004-3821.

19. Galfetti, L.; Merotto, L.; Boiocchi, M.; Maggi, F.; DeLuca, L.T. Ballistic and Rheological Characterization of Paraffin-based Fuels for Hybrid Rocket Propulsion. In Proceedings of the 47th AIAA/ASME/SAE/ASEE Joint Propulsion Conference \& Exhibit (AIAA), San Diego, CA, USA, 31 July-3 August 2011. AIAA Paper No. 2011-5680.

20. Strand, L.D.; Ray, R.L.; Anderson, F.; Cohen, N.S. Hybrid rocket fuel combustion and regression rate study. In Proceedings of the 28th Joint Propulsion Conference and Exhibit, Nashville (AIAA), Nashville, TN, USA, 6-8 July 1992. AIAA Paper No. 1992-3302.

21. Grosse, A.V.; Conway, J.B. Combustion of metals in oxygen. Ind. Eng. Chem. 1958, 50, 663-672. [CrossRef] 
22. DeLuca, L.T.; Maggi, F.; Dossi, S.; Fassina, M.; Paravan, C.; Sossi, A. Prospects of Aluminum Modifications as Energetic Fuels in Chemical Rocket Propulsion. In Chemical Rocket Propulsion: A Comprehensive Survey of Energetic Materials; DeLuca, L.T., Shimada, T., Sinditskii, V.P., Calabro, M., Eds.; Springer: Berlin, Germany, 2017; pp. 191-233.

23. Dossi, S. Mechanically Activated Al Fuels for High Performance Solid Rocket Propellants. Ph.D. Thesis, Politecnico di Milano, Aerospace Science and Technology Department, Milan, Italy, 2014.

24. Dossi, S.; Paravan, C.; Maggi, F.; Galfetti, L. Enhancing micrometric aluminum reactivity by mechanical activation. In Proceedings of the 51st AIAA/SAE/ASEE Joint Propulsion Conference, Orlando, FL, USA, 27-29 July 2015. AIAA Paper No. 2015-4221.

25. Paravan, C.; Dossi, S.; Maggi, F.; Galfetti, L.; Marra, G. Pre-burning characterization of nano-sized aluminum in condensed energetic systems. In Energetic Nanomaterials: Synthesis, Production, and Characterization; Gromov, A.A., Zarko, V.E., Eds.; Elsevier: Amsterdam, The Netherlands, 2016; pp. 341-368.

26. Juergens, L.P.H.; Sloof, W.G.; Tichelaar, F.D.; Mittemeijer, E.J. Structure and morphology of aluminum oxide films formed by thermal oxidation of aluminum. Thin Solid Films 2002, 418, 89-101. [CrossRef]

27. Trunov, M.A.; Schoenitz, M.; Zhu, X.; Dreizin, E.L. Effect of polymorphic phase transformations on $\mathrm{Al}_{2} \mathrm{O}_{3}$ film on oxidation kinetics of aluminum powders. Combust. Flame 2005, 140, 310-318. [CrossRef]

28. Paravan, C.; Verga, A.; Maggi, F.; Galfetti, L. Accelerated ageing of aluminum powders: Metal content, composition, and non-isothermal oxidation reactivity. Acta Astronaut. 2019, 158, 397-406. [CrossRef]

29. Schoenitz, M.; Patel, B.; Agboh, O.; Dreizin, E.L. Oxidation of aluminum powders at high heating rates. Thermochim. Acta 2010, 507, 115-122. [CrossRef]

30. Trunov, M.; Schoenitz, M.; Dreizin, E.L. Ignition of aluminum powders under different experimental conditions. Propellants Explos. Pyrotech. 2005, 30, 36-43. [CrossRef]

31. Sundaram, S.D.; Puri, P.; Yang, V. A general theory of ignition and combustion of nano- and micron-sized aluminum particles. Combust. Flame 2016, 169, 94-109. [CrossRef]

32. Gen, M.Y.; Frolov, Y.V.; Storozhev, V.B. On combustion of particles of subdispersed aluminum. Combust. Explos. Shock Waves 1978, 14, 153-155. [CrossRef]

33. Ivanov, G.V.; Tepper, F. Activated aluminum as stored energy source for propellants. In Challenges in Propellants and Combustion 100 Years after Nobel; Kuo, K.K., Ed.; Begell House: New York, NY, USA, 1997; pp. 636-645.

34. Ilyin, A.P.; Gromov, A.A.; An, V.; Faubert, F.; de Izarra, C.; Espagnacq, A.; Brunet, L. Characterization of aluminum powders I. Parameters of reactivity of aluminum powders. Propellants Explos. Pyrotech. 2002, 27, 361-364. [CrossRef]

35. Gromov, A.A.; Ilyin, A.P.; Förther-Barth, U.; Teipel, U. Characterization of aluminum powders: II. Aluminum nanopowders passivated by non-inert coatings. Propellants Explos. Pyrotech. 2006, 31, 401-409. [CrossRef]

36. Hahma, A.; Gany, A.; Palovuori, K. Combustion of activated aluminum. Combust. Flame 2006, 145, 464-480. [CrossRef]

37. Yogodnikov, D.A.; Andreev, E.A.; Vorob'ev, V.S.; Glotov, O.G. Ignition, combustion, and agglomeration of encapsulated aluminum particles in a composite solid propellant. I. Theoretical study of the ignition and combustion of aluminum with fluorine-containing coatings. Combust. Explos. Shock Waves 2006, 42, $153-155$. [CrossRef]

38. Dreizin, E.; Schoenitz, M. Reactive and Metastable Nanomaterials Prepared by Mechanical Milling. In Metal Nanopowders Production, Characterization, and Energetic Applications; Gromov, A.A., Teipel, U., Eds.; Wiley VCH: Weinheim, Germany, 2014; pp. 227-278.

39. Maggi, F.; Dossi, S.; Paravan, C.; DeLuca, L.T.; Liljedhal, M. Activated aluminum powders for space propulsion. Powder Technol. 2015, 270, 46-52. [CrossRef]

40. Sossi, A.; Duranti, E.; Paravan, C.; DeLuca, L.T.; Vorozhtsov, A.B.; Gromov, A.A.; Pautova, Y.I.; Lerner, M.I.; Rodkevich, N.G. Non-isothermal oxidation of aluminum nanopowder coated by hydrocarbons and fluorohydrocarbons. Appl. Surf. Sci. 2013, 271, 337-343. [CrossRef]

41. Paravan, C.; Reina, A.; Sossi, A.; Manzoni, M.; Massini, G.; Rambaldi, G.; Duranti, E.; Adami, A.; Seletti, E.; DeLuca, L.T. Time-resolved Regression Rate of Innovative Solid Fuel Formulations. In Advances in Propulsion Physics; DeLuca, L.T., Bonnal, C., Haidn, O., Frolov, S., Eds.; Torus Press: Moscow, Russia, 2013; Volume 4, pp. 75-98. 
42. DeLuca, L.T.; Galfetti, L.; Maggi, F.; Colombo, G.; Merotto, L.; Boiocchi, M.; Paravan, C.; Reina, A.; Tadini, P.; Fanton, L. Characterization of HTPB-based solid fuel formulations: Performance, mechanical properties, and pollution. Acta Astronaut. 2013, 92, 150-162. [CrossRef]

43. Zare, A.; Harriman, T.A.; Lucca, D.A.; Roncalli, S.; Kosowski, B.; Paravan, C.; DeLuca, L.T. Mapping of aluminum particle dispersion in solid rocket fuel formulations. In Chemical Rocket Propulsion: A Comprehensive Survey of Energetic Materials; DeLuca, L.T., Shimada, T., Sinditskii, V.P., Calabro, M., Eds.; Springer: Berlin, Germany, 2017; pp. 673-688.

44. Teipel, U.; Förter-Barth, U. Rheology of nano-aluminum suspensions. Propellants Explos. Pyrotech. 2001, 26, 268-272. [CrossRef]

45. Sippel, T.; Son, S.F.; Groven, L.J. Altering the reactivity of aluminum with selective inclusion of polytetrafluoroethylene through mechanical activation. Propellants Explos. Pyrotech. 2013, 38, 286-295. [CrossRef]

46. Sippel, T.R.; Son, S.F.; Groven, L.J.; Zhang, S.; Dreizin, E.L. Exploring mechanisms for agglomerate reduction in composite solid propellants with polyethylene inclusion modified aluminum. Combust. Flame 2015, 162, 846-854. [CrossRef]

47. Terry, B.C.; Son, S.F.; Groven, L.J. Altering combustion of silicon/polytetrafluoroethylene with two-step mechanical activation. Combust. Flame 2015, 162, 1350-1357. [CrossRef]

48. Dossi, S.; Paravan, C.; Maggi, F.; Di Lorenzo, M.; Ardalic, J.; Galfetti, L. Novel activated metal powders for improved hybrid fuels and green solid propellants. In Proceedings of the 52nd AIAA/SAE/ASEE Joint Propulsion Conference, Salt Lake City, UT, USA, 25-27 July 2016. AIAA Paper No. 2016-4596.

49. Chiaverini, M.J.; Serin, N.; Johnson, D.; Lu, Y.C.; Kuo, K.K.; Risha, G.A. Regression Rate Behavior of Hybrid Rocket Solid Fuels. J. Propul. Power 2000, 16, 125-132. [CrossRef]

50. Risha, G.A.; Ulas, A.; Boyer, E.; Kumar, S.; Kuo, K.K. Combustion of HTPB-Based Solid Fuels for Containing Nano-Sized Energetic Powder in a Hybrid Rocket Motor. In Proceedings of the 37th Joint Propulsion Conference and Exhibit, Salt Lake City, UT, USA, 8-11 July 2001. AIAA Paper No. 2001-3535.

51. Risha, G.A.; Boyer, E.; Wehrman, R.B.; Kuo, K.K. Performance Comparison of HTPB-Based Solid Fuels Containing Nano-Sized Energetic Powder in a Cylindrical Hybrid Rocket Motor. In Proceedings of the 38th AIAA/ASME/SAE/ASEE Joint Propulsion Conference \& Exhibit, Indianapolis, IN, USA, 7-10 July 2002. AIAA Paper No. 2002-3576.

52. Risha, G.A.; Evans, B.; Boyer, E.; Wehrman, R.B.; Kuo, K.K. Nano-Sized Aluminum and Boron-Based Solid Fuel Characterization in a Hybrid Rocket Engine. In Proceedings of the 39th AIAA/ASME/SAE/ASEE Joint Propulsion Conference and Exhibit, Huntsville, AL, USA, 20-23 July 2003. AIAA Paper No. 2003-4593.

53. Fanton, L.; Paravan, C.; DeLuca, L.T. Testing and modeling fuel regression rate in a miniature hybrid burner. Int. J. Aerosp. Eng. 2012, 2012, 673838. [CrossRef]

54. Sossi, A.; Duranti, E.; Manzoni, M.; Paravan, C.; DeLuca, L.T.; Vorozhtsov, A.B.; Lerner, M.I.; Rodkevich, N.G.; Gromov, A.A.; Savin, N.L. Combustion of HTPB-based solid fuels loaded with coated nanoaluminum. Combust. Sci. Technol. 2013, 185, 17-36. [CrossRef]

55. Carmicino, C.; Sorge, A.R. Experimental Investigation into the Effect of Solid-Fuel Additives on Hybrid Rocket Performance. J. Propul. Power 2015, 31, 699-713. [CrossRef]

56. Thomas, J.; Petersen, E.L.; DeSain, J.D.; Brady, B.B. Enhancement of Regression Rates in Hybrid Rockets with HTPB Fuel Grains by Metallic Additives. In Proceedings of the 51st AIAA/SAE/ASEE Joint Propulsion Conference, Orlando, FL, USA, 27-29 July 2015. AIAA Paper No. 2015-4041.

57. 3M Material Safety Datasheet. Available online: http://www.machichemicals.com/pdf/3M_FC-2175.pdf (accessed on 19 July 2019).

58. George, P.; Krishnan, S.; Varkey, P.M.; Ravindran, M.; Ramachandran, L. Fuel regression rate enhancement studies in HTPB/GOX hybrid rocket motors. In Proceedings of the 34th AIAA/ASME/SAE/ASEE Joint Propulsion Conference and Exhibit, Cleveland, OH, USA, 13-15 July 1998. AIAA Paper No. 1998-3188.

59. Frederick, R.A.; Whitehead, J.J.; Knox, L.R.; Moser, M.D. Regression rates study of mixed hybrid propellants. J. Propul. Power 2007, 23, 175-180. [CrossRef]

60. Lengellé, G. Solid-Fuel Pyrolysis Phenomena and Regression Rate, Part 1: Mechanisms. In Fundamentals of Hybrid Rocket Combustion and Propulsion; Chiaverini, M.J., Kuo, K.K., Eds.; AIAA Progress in Astronautics and Aeronautics: Reston, VA, USA, 2007; Volume 218, pp. 127-166. 
61. Strand, L.D.; Ray, R.L.; Cohen, N.S. Hybrid rocket combustion study. In Proceedings of the 29th Joint Propulsion Conference and Exhibit (AIAA), Monterey, CA, USA, 28-30 July 1993. AIAA Paper No. 1993-2412.

62. Strand, L.D.; Jones, M.D.; Ray, R.L.; Cohen, N.S. Characterization of hybrid rocket internal heat flux and HTPB fuel pyrolysis. In Proceedings of the 30th Joint Propulsion Conference and Exhibit (AIAA), Indianapolis, IN, USA, 27-29 June 1994. AIAA Paper No. 1994-2876.

63. Paravan, C.; Manzoni, M.; Rambaldi, G.; DeLuca, L.T. Analysis of quasi-steady and transient burning of hybrid fuels in a laboratory-scale burner by an optical technique. Int. J. Energ. Mater. Chem. Propuls. 2013, 12, 385-410. [CrossRef]

64. Chen, S.; Tang, Y.; Zhang, W.; Shen, R.; Yu, H.; Ye, Y.; DeLuca, L.T. Innovative Methods to Enhance the Combustion Properties of Solid Fuels for Hybrid Rocket Propulsion. Aerospace 2019, 6, 47. [CrossRef]

65. Bisin, R.; Paravan, C.; Alberti, S.; Galfetti, L. An Innovative Strategy for Paraffin-based Fuels Reinforcement: Part I, Mechanical and Pre-Burning Characterization. In Proceedings of the 8th European Conference for Aeronautics and Space Sciences (EUCASS 2019), Madrid, Spain, 1-4 July 2019; pp. 1-14.

66. Bisin, R.; Paravan, C.; Verga, A.; Galfetti, L. An Innovative Strategy for Paraffin-based Fuels Reinforcement: Part II, Ballistic Characterization. In Proceedings of the 8th European Conference for Aeronautics and Space Sciences (EUCASS 2019), Madrid, Spain, 1-4 July 2019; pp. 1-14.

67. Grosse, M. Effect of a Diaphragm on Effect of a Diaphragm on Performance and Fuel Regression of a Laboratory Scale Hybrid Rocket Motor Using Nitrous Oxide and Paraffin. In Proceedings of the 45th AIAA/ASME/SAE/ASEE Joint Propulsion Conference \& Exhibit, Denver, CO, USA, 2-5 August 2009. AIAA Paper No. 2009-5113.

68. Yuasa, S.; Shiraishi, N.; Hirata, K. Controlling Parameters for Fuel Regression Rate of Swirling-oxidizer-flow-type Hybrid Rocket Engine. In Proceedings of the 48th AIAA/ASME/SAE/ASEE Joint Propulsion Conference \& Exhibit, Atlanta, GA, USA, 30 July-1 August 2012. AIAA Paper No. 2012-4106.

69. Yuasa, S.; Yamamoto, K.; Hachiya, H.; Kitagawa, K.; Oowada, Y. Development of a small sounding hybrid rocket with a swirling-oxidizer-type engine. In Proceedings of the 37th Joint Propulsion Conference and Exhibit (AIAA), Salt Lake City, UT, USA, 8-11 July 2001. AIAA Paper No. 2001-3537.

70. Ozawa, K.; Kitagawa, K.; Aso, S.; Shimada, T. Hybrid Rocket Firing Experiments at Various Axial-Tangential Oxidizer-Flow-Rate Ratios. J. Propul. Power 2019, 35, 94-108. [CrossRef]

71. Paravan, C.; Glowacki, J.; Carlotti, S.; Maggi, F.; Galfetti, L. Vortex Combustion in a Lab-scale Hybrid Rocket Motor. In Proceedings of the 52nd AIAA/SAE/ASEE Joint Propulsion Conference, Salt Lake City, UT, USA, 25-27 July 2016. AIAA Paper No. 2016-4562.

72. Connell, T.L., Jr.; Yetter, R.A.; Risha, G.A.; Huba, Z.J.; Epsheytn, A.; Fisher, B.T. Enhancement of Solid Fuel Combustion in a Hybrid Rocket Motor Using Amorphous Ti-Al-B Nanopowder Additives. J. Propul. Power 2019, 35, 662-664. [CrossRef]

73. Connell, T.L., Jr.; Risha, G.A.; Yetter, R.A.; Roberts, C.W.; Young, G. Boron and Polytetrafluoroethylene as a Fuel Composition for Hybrid Rocket Applications. J. Propul. Power 2015, 31, 373-385. [CrossRef]

74. Morothiya, G.; Ramakrishna, P.A. Utilization of Mechanical Activated Aluminum in Hybrid Rockets. J. Propul. Power 2018, 34, 1206-1213. [CrossRef]

75. Price, E.W.; Sigman, R.K. Combustion of Aluminized Solid Propellants. In Solid Propellant Chemistry, Combustion, and Motor Interior Ballistics; Yang, V., Brill, T.B., Ren, W.Z., Eds.; AIAA Progress in Astronautics and Aeronautics: Reston, VA, USA, 2000; Volume 185, pp. 66-687.

76. Babuk, V.A.; Vassiliev, V.A.; Sviridov, V.V. Formation of Condensed Combustion Products at the Burning Surface of Solid Rocket Propellant. In Solid Propellant Chemistry, Combustion, and Motor Interior Ballistics; Yang, V., Brill, T.B., Ren, W.Z., Eds.; AIAA Progress in Astronautics and Aeronautics: Reston, VA, USA, 2000; Volume 185, pp. 749-776.

77. DeLuca, L.T.; Galfetti, L.; Colombo, G.; Maggi, F.; Bandera, A.; Babuk, V.A.; Sindistskii, V.P. Microstructure Effects in Aluminized Solid Rocket Propellants. J. Propul. Power 2010, 26, 724-733. [CrossRef]

78. Gany, A. Micro and Nano Scale Phenomena of Aluminum Agglomeration during Solid Propellant Combustion. Eurasian Chem. Technol. J. 2016, 18, 161-170. [CrossRef]

79. Caveny, L.; Gany, A. Breakup of $\mathrm{Al} / \mathrm{Al}_{2} \mathrm{O}_{3}$ Agglomerates in Accelerating Flowfields. AIAA J. 1979, 17, 1368-1371. [CrossRef]

80. Rashkovskii, S.A. Statistical Simulation of Aluminum Agglomeration during Combustion of Heterogeneous Condensed Mixtures. Combust. Explos. Shock Waves 2005, 41, 174-184. [CrossRef] 
81. Jackson, T.; Najjar, F.; Buckmaster, J. New Aluminum Agglomeration Models and Their Use in Solid Propellant Rocket Simulations. J. Propul. Power 2005, 21, 925-936. [CrossRef]

82. Maggi, F.; DeLuca, L.T.; Bandera, A. A Pocket Model for Aluminum Agglomeration Based on Propellant Microstructure. AIAA J. 2015, 53, 3395-4303. [CrossRef]

83. Plaud, M.; Gallier, S. A Numerical Mesoscale Model for Aluminum Agglomeration in Solid Propellants. In Proceedings of the 7th European Conference for Aeronautics and Space Sciences (EUCASS 2017), Milan, Italy, 1-4 July 2017.

84. DeLuca, L.T.; Paravan, C.; Reina, A.; Marchesi, E.; Maggi, F.; Bandera, A.; Colombo, G.; Kosowski, B. Aggregation and Incipient Agglomeration in Metallized Solid Propellants and Solid Fuels for Rocket Propulsion. In Proceedings of the 46th AIAA/ASME/SAE/ASEE Joint Propulsion Conference \& Exhibit, Nashville, TN, USA, 25-28 July 2010. AIAA Paper No. 2010-6752.

85. Purdue University. Heats of Formation and Chemical Compositions. Available online: https://engineering. purdue.edu/ \{\}propulsi/propulsion/comb/propellants.html (accessed on 19 April 2018).

86. Koch, E.C.; Hahma, A.; Klapotke, T.M.; Radies, H. Metal-Fluorocarbon Pyrolants: XI. Radiometric Performance of Pyrolants Based on Magnesium, Perfluorinated Tetrazolates, and Viton-A. Propellants Explos. Pyrotech. 2010, 35, 248-253. [CrossRef]

87. Koch, E.C. (Ed.) Metal-Fluorocarbon Based Energetic Materials; Wiley-VCH Verlag GmbH: Weinheim, Germany, 2012.

88. Biswas, S.W.; Vijaian, K. Friction and wear of PTFE-A review. Wear 1992, 158, 193-211. [CrossRef]

(C) 2019 by the author. Licensee MDPI, Basel, Switzerland. This article is an open access article distributed under the terms and conditions of the Creative Commons Attribution (CC BY) license (http://creativecommons.org/licenses/by/4.0/). 